\section{A) Check for updates}

Cite this: Nanoscale, 2021, 13, 9236

\title{
The detrimental invasiveness of glioma cells controlled by gadolinium chelate-coated gold nanoparticles $\uparrow$
}

\author{
Maxime Durand, ${ }^{a}$ Elodie Lelievre, ${ }^{\mathrm{b}}$ Alicia Chateau, $\neq^{\mathrm{a}}$ Alexandre Berquand, $t^{\mathrm{c}}$ \\ Gautier Laurent, ${ }^{d}$ Philippe Carl, ${ }^{\text {e }}$ Stéphane Roux, ${ }^{d}$ Lise Chazee, ${ }^{b}$ Rana Bazzi, ${ }^{d}$ \\ Frederic Eghiaian, ${ }^{\mathrm{f}}$ Justine Jubreaux, ${ }^{a}$ Philippe Ronde, ${ }^{\mathrm{e}}$ Muriel Barberi-Heyob, ${ }^{a}$ \\ Pascal Chastagner, ${ }^{a}$ Jérôme Devy* $\star^{\mathrm{b}}$ and Sophie Pinel (D * $\star^{a}$
}

\begin{abstract}
Glioblastoma are characterized by an invasive phenotype, which is thought to be responsible for recurrences and the short overall survival of patients. In the last decade, the promising potential of ultrasmall gadolinium chelate-coated gold nanoparticles (namely Au@DTDTPA(Gd)) was evidenced for imageguided radiotherapy in brain tumors. Considering the threat posed by invasiveness properties of glioma cells, we were interested in further investigating the biological effects of AuaDTDTPA(Gd) by examining their impact on GBM cell migration and invasion. In our work, exposure of U251 glioma cells to Au@DTDTPA(Gd) led to high accumulation of gold nanoparticles, that were mainly diffusely distributed in the cytoplasm of the tumor cells. Experiments pointed out a significant decrease in glioma cell invasiveness when exposed to nanoparticles. As the proteolysis activities were not directly affected by the intracytoplasmic accumulation of AuADTDTPA(Gd), the anti-invasive effect cannot be attributed to matrix remodeling impairment. Rather, Au@DTDTPA(Gd) nanoparticles affected the intrinsic biomechanical properties of U251 glioma cells, such as cell stiffness, adhesion and generated traction forces, and significantly reduced the formation of protrusions, thus exerting an inhibitory effect on their migration capacities. Consistently, analysis of talin-1 expression and membrane expression of beta 1 integrin evoke the stabilization of focal adhesion plaques in the presence of nanoparticles. Taken together, our results highlight the interest in Au(DTDTPA(Gd) nanoparticles for the therapeutic management of astrocytic tumors, not only as a radio-enhancing agent but also by reducing the invasive potential of glioma cells.
\end{abstract}

Received 17th December 2020, Accepted 21st March 2021 DOI: $10.1039 / \mathrm{d} 0 \mathrm{nr} 08936 \mathrm{~b}$ rsc.li/nanoscale including pre-existing blood vessels, white matter tracts and the subarachnoid space. The high migratory capability of these tumor cells is thought to be responsible for the short overall survival of GBM patients, since infiltrative cells always remain following cytoreductive surgery and lead to recurrence. Unfortunately, several experimental converging clues suggest that migration/invasion abilities of glioblastoma cells could be enhanced by therapeutic intervention such as surgical excision or irradiation. ${ }^{1}$

In a recent review, we presented how the rapid development of nanomedicine for cancer applications opens up new perspectives for GBM therapy and imaging-guided treatments. Among promising innovations, many preclinical studies are ongoing to investigate the potential of gold nanoparticles as a drug delivery system, to enhance external beam radiotherapy or to induce photothermal ablation. ${ }^{2}$ The lack of significant cell toxicity in a wide concentration range may explain the craze for the use of gold nanoparticles (AuNPs) in cancer therapies. In this therapeutic context, gold nanoparticles with a dia- 
meter smaller than $10 \mathrm{~nm}$ should be preferred because (i) they can be eliminated by renal clearance which is a pre-requisite for the in vivo application of non-biodegradable nanoparticles ${ }^{3}$ and (ii) they are more efficient than large nanoparticles for enhancing the radiation dose effect. ${ }^{4}$ In accordance with these prerequisites, Roux's research group has developed ultrasmall polyaminocarboxylate-coated gold nanoparticles, namely Au@DTDTPA, that exhibit a promising potential for imageguided radiotherapy for brain tumors. Au@DTDTPA nanoparticles behave as positive contrast agents for magnetic resonance imaging (MRI) and as radiotracers for nuclear imaging (planar scintigraphy and single photon emission computed tomography (SPECT)) when they are labeled with $\mathrm{Gd}^{3+}$ and ${ }^{99 m} \mathrm{Tc}^{4+}$ or ${ }^{111} \mathrm{In}^{3+}$ ions, respectively. After intravenous injection, authors showed that these nanoparticles are removed from the body mainly by renal excretion. Furthermore, X-ray irradiation 5-10 minutes after intravenous administration of Au@DTDTPA(Gd) increased the life span of rats bearing brain tumor by a factor 2 in comparison with animals treated only by radiotherapy. ${ }^{5}$

Despite the lack of major toxicity of gold nanoparticles, some articles have reported that AuNP internalization by cells can affect cell proliferation, migration and invasion, and alter metabolic activity and reprogram secretome. For example, Pernodet et al. found that actin stress fibers disappeared and properties such as cell spreading, cell adhesion, and cell growth were altered dramatically as a result of intracellular gold nanoparticle presence in human dermal fibroblasts. ${ }^{6}$ Similarly, gold nanoparticles seem to be able to reduce tumor growth and metastasis. ${ }^{7,8}$

Knowing that migrating cells remain a major threat for glioblastoma-bearing patients, these recent data about AuNPs led us to further investigate the potential of Au@DTDTPA(Gd) and to examine their effects on GBM cell migration and invasion. Glioma cell invasion is a complex multi-step biological process that is regulated by an integrated network of biochemical and biomechanical events, involving many changes in morphological and adhesion properties and microenvironment remodeling. In this context, different in vitro approaches such as 3D spheroid tumor invasion assays, scratch assay and cell tracking by time-lapse video microscopy, traction force microscopy or atomic force microscopy, allowed us to obtain more insight into migration/invasion properties of glioblastoma cells when exposed to Au@DTDTPA(Gd) nanoparticles.

\section{Results and discussion}

\section{Au@DTDTPA(Gd) nanoparticle uptake and consequences on cell viability and proliferation}

In the past two decades, many studies have demonstrated that cellular uptake depends on the nanoparticle size, shape and coating. ${ }^{9-11}$ The cellular accumulation of gold nanoparticles was time- and concentration-dependent until a steady-state ${ }^{9-11}$ and quantitative and qualitative distribution appeared as a key parameter that affects direct cytotoxicity and therapeutic activity such as radiosensitizing potential. ${ }^{12,13}$ Hence, the first step aimed at quantifying intracellular gold after glioma cell exposition to Au@DTDTPA(Gd) and evaluating consequences on cell viability and proliferation.

Elemental Au quantification by inductively coupled plasma mass spectrometry (ICP-MS) revealed that after $24 \mathrm{~h}$ of exposure, the quantity of $\mathrm{Au}$ accumulated in U251 cells was similar regardless of the concentration of nanoparticles used ( 1 and $5 \mathrm{mM}$ ). The number of Au@DTDTPA(Gd) nanoparticles taken up reached about $6 \times 10^{5}$ to $7 \times 10^{5}$ per cells (Table 1 ). STED microscopy experiments were conducted using cyanine 3-labeled Au@DTDTPA(Gd) and markers of particular compartments (i.e. antibodies directed against EEA1 for endosomes, calnexin for rough endoplasmic reticulum, vinculin for focal adhesion complexes and CoxIV for mitochondria (Fig. 1A-D)), to know the precise subcellular distribution of nanoparticles. Nanoparticles clearly accumulate in the cytoplasm in a diffuse pattern, while fluorescence is also observable in punctate structures at the periphery of the nucleus (Fig. 1E). Surprisingly, we did not notice small or large clusters of nanoparticles in cytoplasmic vesicles such as endosomes or in focal adhesion complexes. The ultrasmall size of Au@DTDTPA(Gd) nanoparticles and the lack of endosome/ lysosome-confined intracellular clusters render nanoparticles undetectable by the usually used transmission emission microscopy. Similarly, Huang et al. have synthetized $2 \mathrm{~nm}$, $6 \mathrm{~nm}$ and $15 \mathrm{~nm}$-sized gold nanospheres and used tiopronin, a pharmaceutical drug including a thiol group, as a stabilizing agent. The authors quantified $5 \times 10^{5}$ to $5 \times 10^{6}$ nanoparticles per cell in a breast cancer monolayer model and they showed that the 2 and $6 \mathrm{~nm}$ AuNPs mostly localized in the cytoplasm without any aggregation and also about $15 \%$ were able to enter the nucleus. ${ }^{11}$ Afterwards, Boyoglu et al. confirmed that $3 \mathrm{~nm}$ and $10 \mathrm{~nm}$ AuNPs are efficient at entering the cytoplasm and nucleus of Hep-2 cells. ${ }^{14}$

Even if gold materials are generally considered to be bioinert, nontoxic and biocompatible, nanoscale gold particles may have much higher bioactivity due to their increased "surface area to volume ratio" that can result in direct cytotoxicity. Induction of apoptosis, cell cycle delay or generation of reactive oxygen species were described as potential cytotoxic effects of gold nanoparticles, according to their physicochemical properties. ${ }^{15,16}$

Table 1 Quantification of gold in the U251 cells based on ICP-OES analysis. U251 cells maintained as monolayer culture were exposed for $24 \mathrm{~h}$ to Au@DTDTPA(Gd) at 1 or $5 \mathrm{mM}$. After nanoparticles removal, the cells were rinsed, detached, counted and centrifuged to obtain a pellet. Samples were then mineralized and proceeded as described in Experimental section

\begin{tabular}{lll}
\hline $\begin{array}{l}\text { Au@DTDTPA(Gd) } \\
\text { concentration }\end{array}$ & $\begin{array}{l}\text { Gold quantity } \\
(\mu \mathrm{g})\end{array}$ & Nanoparticles per cell \\
\hline $1 \mathrm{mM}$ & $0.48 \pm 0.042$ & $6.17 \times 10^{6} \pm 5.65 \times 10^{4}$ \\
$5 \mathrm{mM}$ & $0.55 \pm 0.037$ & $6.99 \times 10^{6} \pm 5.46 \times 10^{4}$
\end{tabular}


A.
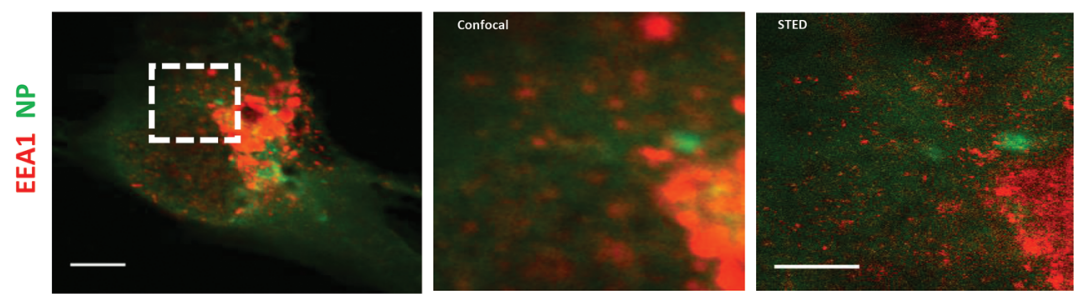

B.

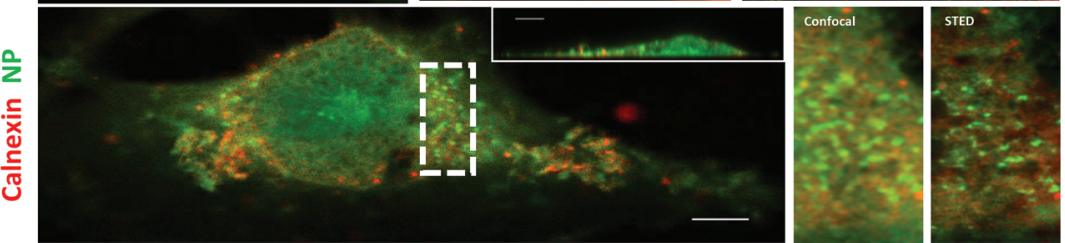

c.
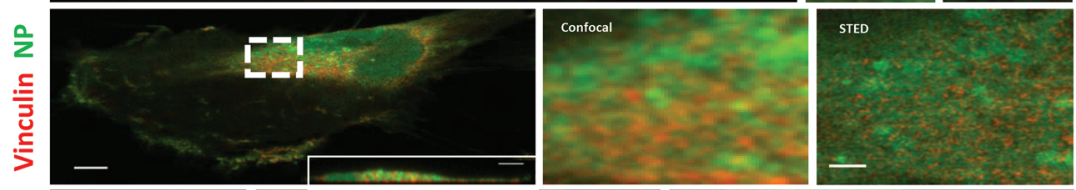

D.

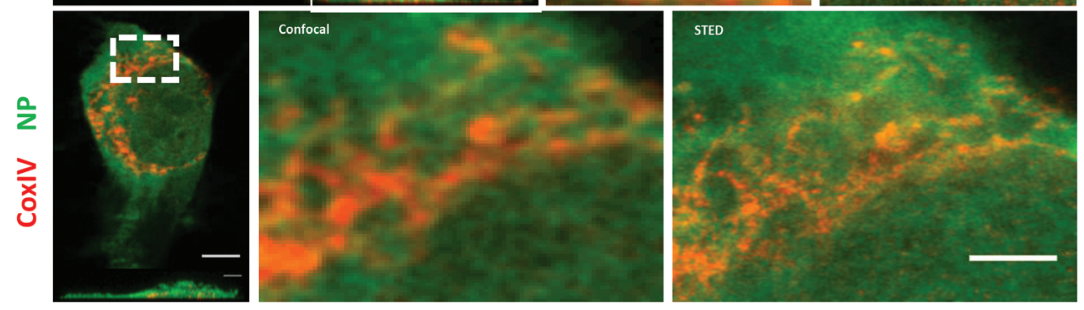

E.
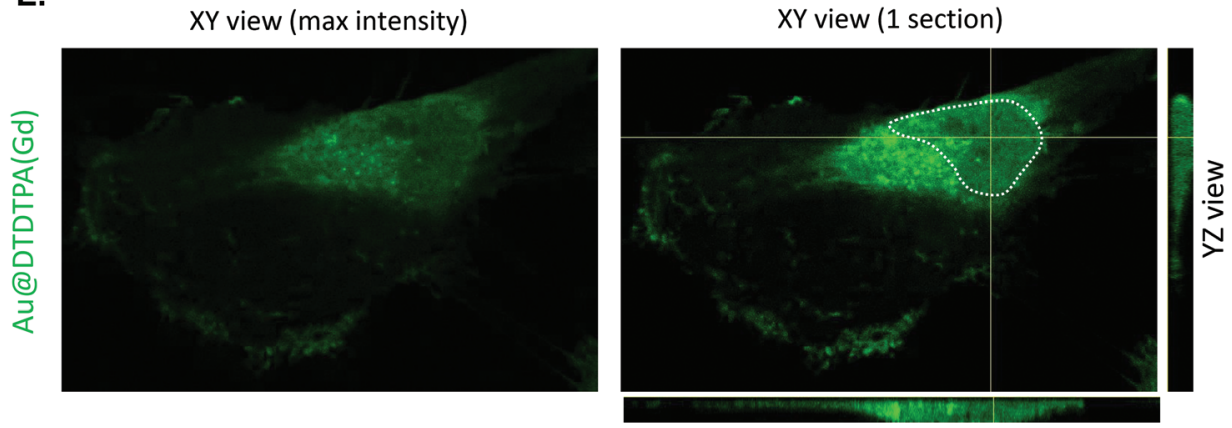

F.

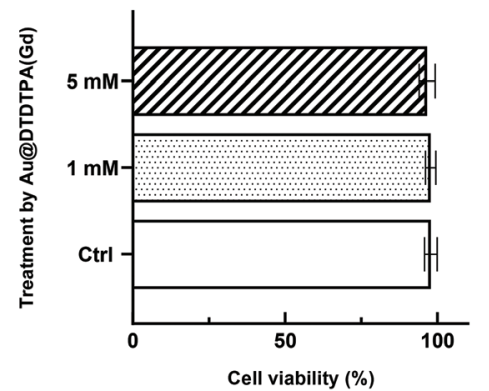

XZ view

Fig. 1 Localization of Au@DTDTPA(Gd) nanoparticles in U251 cells. (A-D) To know precisely subcellular distribution of Au@DTDTPA(Gd) nanoparticles, confocal and STED microscopy experiments were conducted using cyanine3-labeled Au@DTDTPA(Gd) (green fluorescence) and markers of particular compartments (red fluorescence): antibodies labelled with STAR RED were directed against (A) EEA1 for endosomes, (B) calnexin for rough endoplasmic reticulum, (C) vinculin for focal adhesion complexes and (D) CoxIV for mitochondria. Left panel: confocal overview of a fixed cell (scale bar $5 \mu \mathrm{m}$ ). A region delineated by dotted white rectangle is the zoomed in confocal (middle panel) and STED (right panel) image (scale bar $2 \mu \mathrm{m})$. (E) Maximal image intensity in $X Y, X Z$, and $Y Z$ sections through the U251 nuclei after Au@DTDTPA(Gd)-Cy3 exposure (1 mM). XY section shows one slice through the nucleus of a single U251 cell; the XZ section shows a cut along the horizontal yellow line through the nucleus; the $Y Z$ section shows a cut along the vertical yellow line through the nucleus. The white dotted line delineates the nucleus of the cell. The green fluorescence signal corresponds to Au@DTDTPA(Gd): only the nanoparticles that cross the given cut are visible. The green intensity profile indicates a strong accumulation of nanoparticles at the periphery of the nucleus as well as their presence to a lesser extent in the nucleus. (F) Based on trypan blue exclusion assay and a TC20 ${ }^{\mathrm{TM}}$ automated cell counter, viable cells were determined in control cell cultures (Ctrl) or $24 \mathrm{~h}$ after exposure to Au@DTDTPA(Gd) nanoparticles (1 $\mathrm{mM}$ or $5 \mathrm{mM})$. Results are presented as mean $\pm \mathrm{SD}(n \geq 4)$. 
With $97 \%$ cell viability following a $24 \mathrm{~h}$ exposure, no direct toxic effects were noticed on U251 cells despite the strong internalization of nanoparticles in cancer cells (Fig. 1F). When the global behavior of U251 glioma cells was followed for $70 \mathrm{~h}$ with a cell-impedance measurement system (xCELLigence realtime cell analysis system), no alteration was noticed for nanoparticle-treated cells (data not shown). Using flow cytometry, we also investigated the influence of gold nanoparticles on cell cycle distribution and the proliferation index (i.e. percent $\mathrm{S}$ phase + percent G2/M phase) was calculated as previously described. ${ }^{17}$ Sixteen hours after the removal of Au@DTDTPA (Gd) nanoparticles, the proliferation index of U251 glioma cells treated with gold nanoparticles was unchanged as compared to untreated cells (ESI SI $\uparrow$ ).

Collectively, our results indicate that the concentrations of the Au@DTDTPA(Gd) nanoparticles used in this study are lower than those affecting the viability and proliferation of U251 glioblastoma cells.

\section{Au@DTDTPA(Gd) nanoparticles reduced the invasion abilities of glioma cells}

Both in patients and in vitro models, glioblastoma cells are well-known to exhibit a highly invasive behavior leading to diffuse infiltration of the surrounding. ${ }^{18}$ To explore and decipher the mechanisms developed by invading cells in glioblastoma, the invasive behavior of the U251 cell line was extensively studied using a variety of methods and materials to mimic the in vivo microenvironment (2D or 3D extracellular matrix, organotypic slice). Multicellular tumor spheroids embedded in a 3D matrix represent invaluable tools to analyze cell invasion and to mimic the cancer microenvironment. ${ }^{19,20}$ We have investigated the impact of Au@DTDTPA(Gd) nanoparticles on invasive capacities of U251 cells. For this purpose, U251 spheroids were exposed to 1 and 5 mM Au@DTDTPA(Gd) nanoparticles for $24 \mathrm{~h}$ and then, embedded in a matrix mixing Matrigel ${ }^{\circledR}$ and hyaluronic acid. As recently published, we have previously confirmed that Au@DTDTPA(Gd) nanoparticles were able to diffuse and be distributed throughout the spheroids, reaching the center of the tumor. ${ }^{21}$ Fig. 2 shows representative images of U251 spheroids in their 3D matrix 4 days postseeding. While the dark areas correspond to spheroids' cores including necrotic, quiescent and proliferative cells, we can notice the cells on the edge that radially extend into the matrix (Fig. 2A). Some of them seem to move individually (black arrows) while other organized in clusters (denser areas), suggesting collective cell motion (white arrows) (Fig. 2B). To assess the effect of Au@DTDTPA(Gd) nanoparticles on U251 invasiveness, spheroid initial/end sizes and invasiveness areas were determined. With or without exposure to nanoparticles, the central core similarly grew during the culture to reach the mean final size of $0.516 \pm 0.028 \mathrm{~mm}^{2}, 0.420 \pm 0.076 \mathrm{~mm}^{2}$ and $0.494 \mathrm{~mm}^{2} \pm 0.026 \mathrm{~mm}^{2}$ for untreated-, $1 \mathrm{mM}$ and $5 \mathrm{mM}$ nanoparticle-treated spheroids, respectively. As shown in Fig. 2C, the invasion capacities of the U251 cells pretreated with Au@DTDTPA(Gd) were approximately 20-25\% lower than those of the control cells: invasion distances and invasion areas reached respectively, $820 \pm 16 \mu \mathrm{m}$ and $3.570 \pm 0.135 \mathrm{~mm}^{2}$ for untreated control spheroids; $644 \pm 14 \mu \mathrm{m}$ and $2.719 \pm$ $0.154 \mathrm{~mm}^{2}$ for $1 \mathrm{mM}$ nanoparticle-treated spheroids $(p<0.005$ vs. Ctrl); $678 \pm 21 \mu \mathrm{m}$ and $2.899 \pm 0.147 \mathrm{~mm}^{2}$ for $5 \mathrm{mM}$ nanoparticle-treated spheroids ( $p<0.005 v s$. Ctrl). Thus, 3D invasion assays revealed a significant inhibitory effect of our ultrasmall gold nanoparticles on invasive capacities of U251. Inhibitory effects were previously described by Zhou et al. for breast, prostate and melanoma cancer cells exposed to gold nanorods using transwell invasion assays. ${ }^{22}$ Similarly, Au@Pt nanoseeds have been shown to reduce the invasiveness of kidney cancer cells in Boyden chambers. ${ }^{23}$

To overcome the structural restraints of brain tissue organization, invading glioma cells need remarkable plasticity and proteolytic activity allowing them to move through the brain parenchyma, along the blood vessels and white matter tracks. ${ }^{24}$ In this context, we were interested in studying the impact of Au@DTDTPA(Gd) uptake in the first step, on proteolysis abilities of U251 cells and in the second step, on intrinsic cell plasticity and motility.

\section{Impact of Au@DTDTPA(Gd) nanoparticle uptake on proteolytic activity and on glioma cell motility}

Matrix metalloproteinases (MMPs) like serine proteases urokinase plasminogen activators constitute the main groups of proteases capable of degrading extracellular matrix proteins (fibronectin, type IV-collagen, proteoglycan, etc) and are involved in GBM growth and dissemination. A strong correlation exists between elevated levels of urokinase plasminogen activators (UPA) and MMPs with cancer progression, metastasis and shortened patient survival. ${ }^{25}$

Concerning the MMP family, gelatinases MMP-2 and MMP-9 and the membrane-type MT1-MMP are found to be expressed by glioma cells and already described for their contribution in tumor progression. ${ }^{26}$ Moreover, a previous study has demonstrated the downregulation of MMP-2 and -9 expression after the exposure of papillary thyroid carcinoma cells to $10 \mathrm{~nm}$ AuNPs at a dose of $50 \mu \mathrm{g} \mathrm{mL}{ }^{-1} \cdot{ }^{27}$ Thus, we explored the effects of Au@DTDTPA(Gd) on metalloprotease expression and activity. RT-qPCR analysis indicated that U251 cells expressed MT1-MMP and MMP-2, but not MMP-9. Exposure to Au@DTDTPA(Gd) induced a slight but not significant decrease in MT1-MMP and MMP2 mRNA levels. Using the gelatin zymography method, we focused on proteolytic activity of gelatinases. In accordance with others, ${ }^{28}$ we did not detect any gelatinolytic activity of MMP-2 nor MMP-9 in conditioned media of U251 cells, even in untreated samples. MT1-MMP analysis was performed by using a biotinylation approach in order to recover only active MT1-MMP at the cell membrane. Proteolytic activity of MT1-MMP was found in untreated U251 at the same level as after Au@DTDTPA(Gd) nanoparticle uptake (ESI SI $2 \dagger$ ).

Thus, the MMPs do not seem to be involved in the reduced invasive capabilities of U251 cells treated with NPs. The plasminogen/plasmin system is another system well described for its involvement in the extracellular matrix degradation during 
A

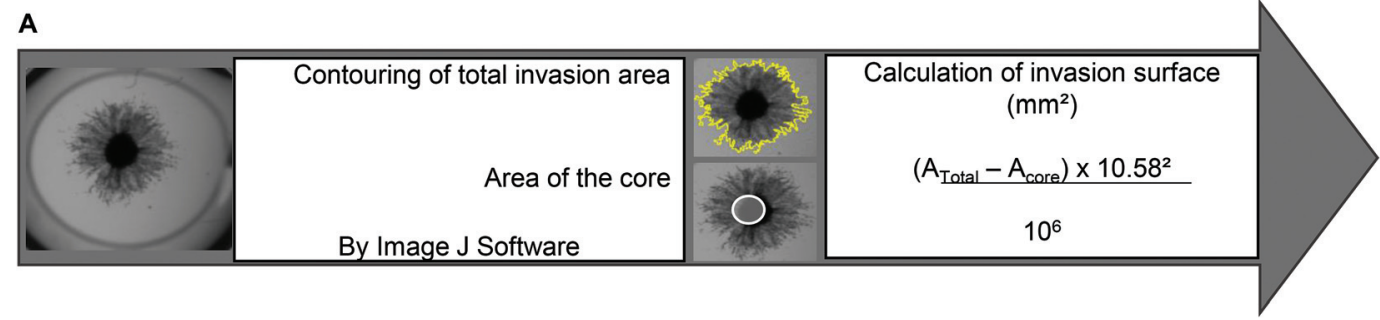

B

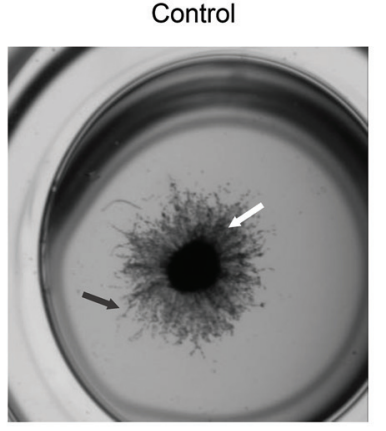

Au@DTDTPA(Gd) 5mM

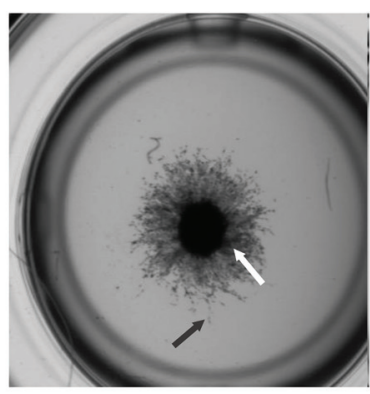

C

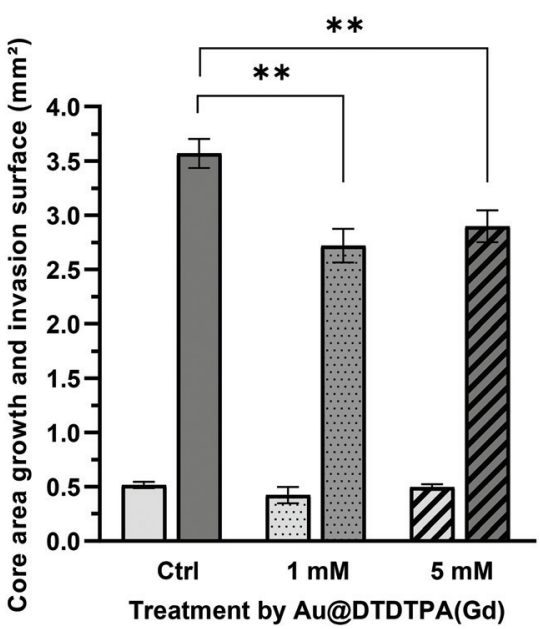

Fig. 2 Impact of Au@DTDTPA(Gd) nanoparticles on U251 invasiveness based on 3D invasion assay. U251 spheroids ( 450 $\pm 70 \mu \mathrm{m}$ in diameter) were exposed to 1 or $5 \mathrm{mM}$ Au@DTDTPA(Gd) for $24 \mathrm{~h}$. After nanoparticle removal, the spheroids were seeded in 6-well culture plates (one spheroid per well) and each one was embedded in a mixture of Matrigel ${ }^{\circledR}$, complete culture medium enriched with hyaluronic acid. (A) Using ImageJ software, the total area of invasion (manual yellow delineation) and the core area (white delineation) were determined 4 days after seeding for each spheroid, allowing calculation of the "invasion surface" (1 pixel $=10.58 \mu \mathrm{m})$. (B) Representative images of invasion for untreated- or Au@DTDTPA (Gd)-treated spheroids showed areas of collective (white arrows) and individual (black arrows) invasion. (C) Histograms represent the core growth (left histograms) and the invasion surface (right histograms) for untreated- or Au(DDTDTPA(Gd)-treated spheroids. Results are presented as mean \pm SD ( $n \geq 11$ spheroids for at least $n \geq 3$ independent experiments). ${ }^{* *} p<0.01$ according to the Mann-Whitney $U$ test.

GBM progression. ${ }^{29}$ Notably, the serine protease urokinase plasminogen system (UPA, UPAR) participates actively in ECM restructuring through plasmin and MMPs activation. Our preliminary analyses using RTqPCR on cell lysates and proteome arrays on conditioned media did not show noteworthy influence of NPs on the plasminogen/plasmin system (data not shown).

While the reduced abilities of invasion of U251 after Au@DTDTPA(Gd) endocytosis cannot be directly explained by the interference of the nanoparticles with the proteolysis processes, we questioned whether the nanoparticles can affect the migration capabilities of glioma cells. Glioblastoma cells show a versatile repertoire of migration modes, allowing them to adapt their strategies in response to changing environmental conditions. Indeed, these tumor cells can exhibit individual (amoeboid or mesenchymal) or collective migration modes, depending on the local properties of the extracellular matrix. ${ }^{30}$ In this regard, different tests were carried out to evaluate the effects of Au@DTDTPA(Gd) on migration capacities of U251 cells.

A scratch assay which is considered as the standard in vitro technique was firstly performed for probing collective cell migration in two dimensions. ${ }^{31}$ Images were captured immediately $(0 \mathrm{~h})$ and $16 \mathrm{~h}$ after the scratch and surface of the healing wound was determined using imageJ software (Fig. 3A). At the end point of the experiment, the healing area reached $33 \%$ for the control. After exposure to nanoparticles, the recovery of the wounded area was only $15 \%$, i.e. 2 times less than that in the control samples (Fig. 3B).

Then, time-lapse video microscopy and cell tracking experiments were performed on monodisperse cells to estimate cell velocity and directionality. While traditional methods rely on Boyden chamber migration assays to measure individual migration in response to chemotactic signals, we preferred time-lapse video microscopy because it allows the measurement of individual migration parameters and the visualization of morphological changes that cell undergoes during migration. $^{32}$ In untreated U251 cells, movies revealed a repeated sequential polarized apparition of enlarged lamellipodia associated with cell polarity and directional displacement of cells with typical mesenchymal morphologies (Movie $1 \dagger$ left).

Looking at each cell individually, exposition to Au@DTDTPA(Gd) seems to interfere with cell polarity estab- 
A

Control
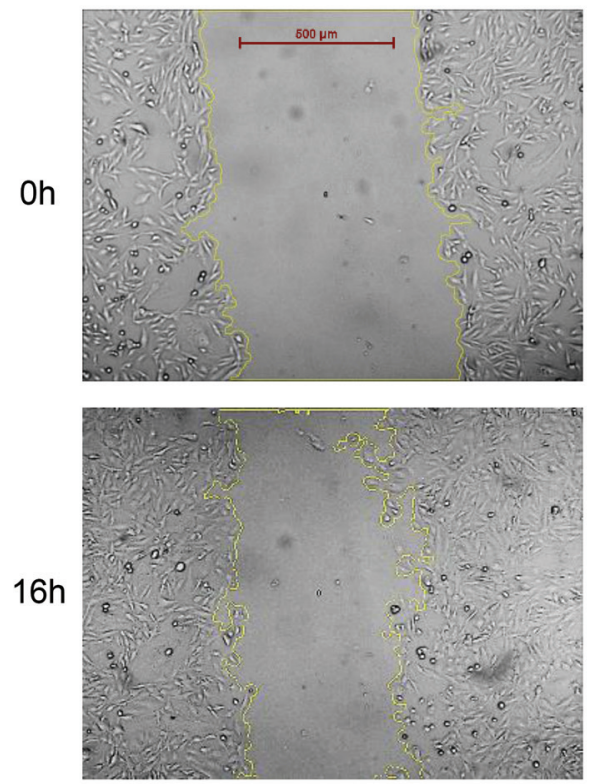

C

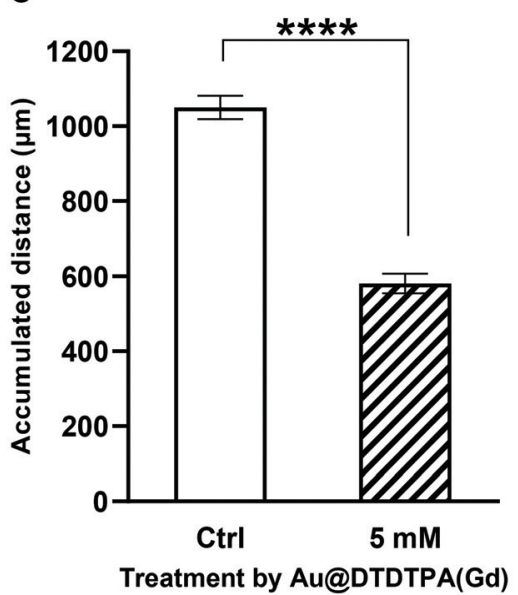

Au@DTDTPA(Gd) 5mM
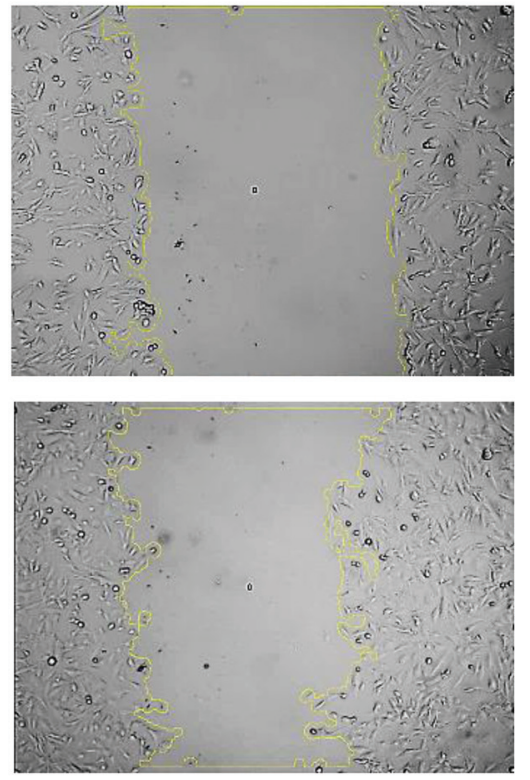

D

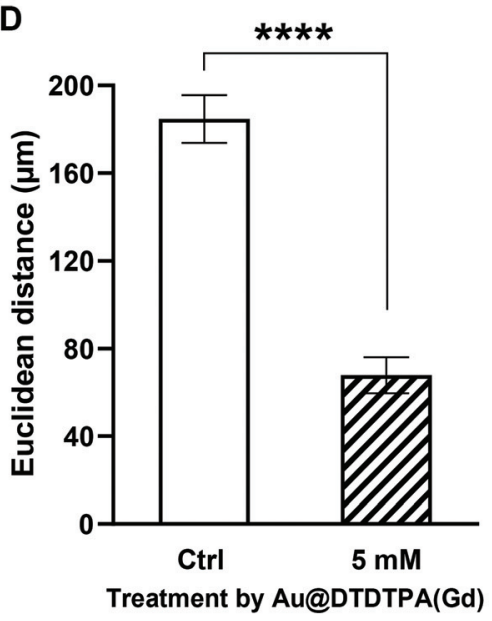

B

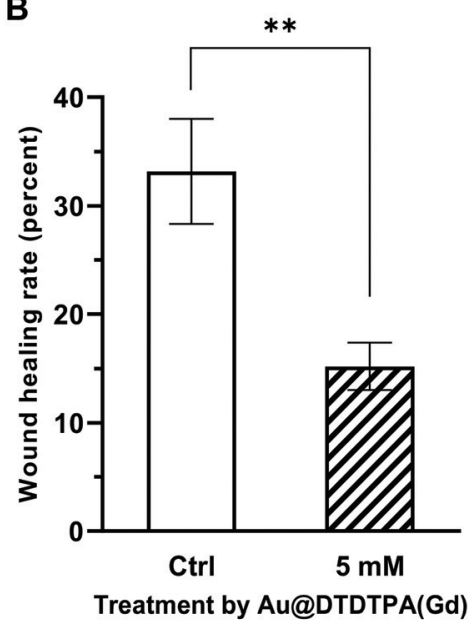

E

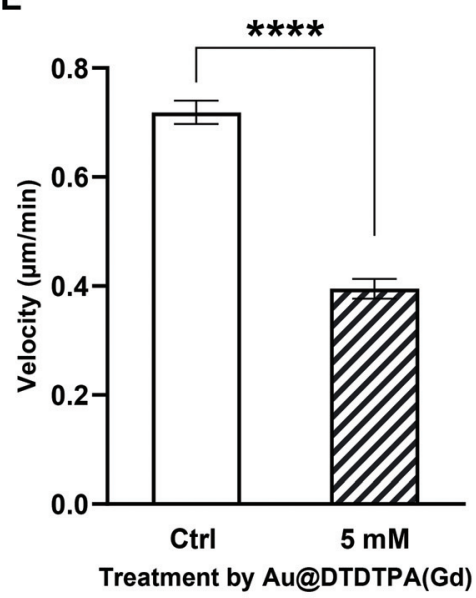

Fig. 3 Impact of Au@DTDTPA(Gd) nanoparticles on collective and individual migration of U251 cells. (A and B) Collective migration of U251 glioma cells was assessed using wound healing assays. As soon as the nanoparticles were removed, a scratch was made into the confluent monolayer of U251 cells and (A) photographs at $\times 40$ magnification were captured immediately and $16 \mathrm{~h}$ after scratching. Representative images show the gap filling under control conditions (Ctrl) or after $24 \mathrm{~h}$ of exposure to $5 \mathrm{mM}$ AuADTDTPA(Gd) nanoparticles (scale bar $800 \mu \mathrm{m}$ ). (B) The plugin "MRI wound healing assay tool" from ImageJ software was used to measure the gap area at $0 \mathrm{~h}$ and $16 \mathrm{~h}$, and calculate the wound healing rates as plotted on histograms. The results are presented as mean \pm SD ( $n=8$ independent experiments). (C-E) Individual migration was monitored by video microscopy. After seeding on fibronectin-coated coverslip, 48 untreated or nanoparticle-treated cells were individually tracked for $24 \mathrm{~h}$ by video microscopy ( $\times 20$ magnification objective, using a Zeiss Axio Observer). Histograms represent (C) accumulated distance (D) Euclidean distance (E) and velocity. Results are presented as mean \pm SD. ${ }^{* *} p<0.01$ and ${ }^{* * * *} p<0.0001$ according to the Mann-Whitney $U$ test.

lishment, as we observed a fast turnover of lamellipodia in any direction that leads to both reduced directional displacement and reduced apparent velocity (Movie $1 \dagger$ right). Indeed, cell tracking quantification revealed that U251 cells seeded onto fibronectin exhibit a velocity of $0.72 \pm 0.02 \mu \mathrm{m} \mathrm{min}{ }^{-1}$ and the traveled distance reached $1050 \pm 31 \mu \mathrm{m}$ per $24 \mathrm{~h}$. U251 cell motility rates were significantly altered after nanoparticle endocytosis, because U251 cell velocity was decreased by $43 \%$ $\left(0.39 \pm 0.02 \mu \mathrm{m} \min ^{-1}\right)$, the traveled distance by $45 \%(581 \pm$
$26 \mu \mathrm{m}$ per $24 \mathrm{~h}$ ) and directional cell migration (Euclidian distance) by $65 \%$ compared to untreated cells (Fig. 3C-E).

Together, these results indicate that Au@DTDTPA(Gd) can exert a significant inhibitory effect on both collective and individual migration of U251 cells. Our specific observations for the Au@DTDTPA(Gd) nanoparticles can probably be generalized to most of the gold nanoobjects. Indeed, several previous studies using wound healing assay or a transwell chamber have reported that gold nanospheres and gold nanorods, 
regardless of their size, their concentration or the cell lines used, could reduce tumor cell migration. For example, Zhou et al. showed decreased chemotactic responses in a transwell chamber when breast, prostate or skin cancer cells were exposed to gold nanorods. ${ }^{22}$ More recently, Li et al. performed wound healing assays and demonstrated that gold nanospheres reduced liver cancer cell migration. ${ }^{33}$ Similarly, timelapse video microscopy of wound healing of lung and prostate cancer cells has shown that gold nanospheres affect early cell migration $(6 \mathrm{~h})$ with decreased gap filling. ${ }^{34}$

\section{Au@DTDTPA(Gd) nanoparticle uptake affects the intrinsic biomechanical properties of glioma cells and cell-ECM interactions}

From a biomechanical standpoint, tumor cell motion in case of mesenchymal migration requires cell deformation and active generation of traction force on the underlying extracellular matrix to pull the cell forward. Cell deformation is directly dependent on the stiffness properties and the transition to a motile phenotype is characterized by changes in focal adhesion and cytoskeletal dynamics. Previous studies have reported a correlation between cell stiffness and metastatic potential of cancer cells ${ }^{7}$ and that cancer cells are softer than normal cells. ${ }^{35}$ Then, we investigated the impact of Au@DTDTPA(Gd) on the deformability and stiffness of U251 by using AFM-indentation measurements and by Young's modulus determination. In this case, an isolated cell was taken out of a cell culture on fibronectin coated coverslip and AFM measurements were realized in areas outside the nucleus, where the cell height was at least 3 times superior to the indentation depth in order to calculate Young's modulus. Young's modulus was found to be remarkably stable on control cells with values equal to $1.61 \pm 0.17 \mathrm{kPa}$. After Au@DTDTPA(Gd) uptake, Young's modulus dramatically increased to reach $4.56 \pm 2.58 \mathrm{kPa}$ on fibronectin (Fig. 4A). Moreover, it is well documented that cell migration is dependent on lamellipodial protrusions. ${ }^{36}$ Using AFM error images, we have analyzed the number of membrane protrusions and demonstrated that treatment with Au@DTDTPA(Gd) induced a decrease of about $50 \%$ in the protrusion number $(5.30 \pm 0.39$ protrusions per $100 \mu \mathrm{m}^{2}$ for the control samples vs. $2.43 \pm 0.31$ protrusions per $100 \mu \mathrm{m}^{2}$ for the treated cells) (Fig. 4B). All these results highlighted the potential of NPs to diminish the capacities of U251 cells to displace.

In order to explain and correlate the increase in Young's modulus and the decrease in the migration capabilities of U251 cells after Au@DTDTPA(Gd) treatment, fluorescently labeled phalloidin has been used to study actin cytoskeleton organization by confocal microscopy. ESI SI $3 \uparrow$ shows the 3D isosurface reconstruction of cells using 2 different thresholds for untreated control cells or nanoparticle-treated cells. At the lowest threshold (Fig. 4C), a clear difference appears in the actin labeling between untreated and Au@DTDTPA(Gd)treated cells. While only the actin cortex is visible in control cells, the Au@DTDTPA(Gd)-treated cells exhibit well-developed intracellular stress fibers and a thicker actin cortex. Adhesion structures appear clearly at the edge of U251 cells and more actin patches with the highest threshold value (framed areas) are present in nanoparticle-treated cells. Our observations corroborate previously published studies that reported changes in F-actin fiber organization when cells were exposed to inorganic nanoparticles. ${ }^{37}$ More recently, Mulens-Arias et al. showed that AuNPs disturbed the adhesive structures and affected focal adhesion dynamics, in particular, characterized by an increase or a decrease in mature focal adhesion in the first $2 \mathrm{~h}$ following exposure according to the type of cells studied (mesenchymal stem cells or endothelial cells, respectively). Nevertheless, the effects appear to be dependent on the nanoparticle core size and cell type. ${ }^{38}$ Consistently, we conducted further molecular investigations to determine how Au@DTDTPA(Gd) interferes with the actin cytoskeletal system. Thus, we studied by immunoblotting the membrane expression of beta 1 integrin in biotinylated extracts (Fig. 4D and E) and expression of Talin1 (Fig. 4F). While no difference in the total beta 1 integrin expression was noticed between untreated- and nanoparticletreated cells, membrane expression of beta 1 integrin was doubled when U251 cells were exposed to 5 mM Au@DTDTPA (Gd) nanoparticles. In parallel, Talin-1 expression, an ubiquitous cytosolic protein that is found in high concentrations in focal adhesions, was markedly increased in Au@DTDTPA(Gd)treated cells. These results evoke the stabilization of focal adhesion plaques in the presence of nanoparticles, confirming the disturbance of focal adhesion dynamics. ${ }^{39}$

To adhere and migrate, cells generate traction forces through the cytoskeleton. ${ }^{40}$ So, using time-lapse traction force microscopy (TFM), we examined the differences in traction forces generated by $\mathrm{U} 251$ cells pre-exposed or not to Au@DTDTPA(Gd) nanoparticles (Movie 2†). Traction force microscopy yields a spatial image of the stress exerted by the cells on elastic gel substrates. As a cell attaches to the surface of the substrate, it deforms the substrate proportionally to the applied mechanical force and these elastic deformations can be followed by video microscopy and described quantitatively with high precision. ${ }^{41}$ Under moderate stiffness mimicking conditions in healthy and tumor brain tissues $(E=5$ to 15 $\mathrm{kPa}),{ }^{42}$ measurements of cellular force indicate that after $24 \mathrm{~h}$ of exposure to Au@DTDTPA(Gd), U251 glioma cells exhibit stronger traction stresses compared to the non-exposed cells (Fig. 5A and B) with the force ratios reaching $13410 \pm 381 \mathrm{~Pa}$ $\mu \mathrm{m}^{-2}$ and $18056 \pm 616 \mathrm{~Pa} \mu \mathrm{m}^{-2}(p=0.0047)$, respectively. These data confirm that nanoparticles accumulated in the cell cytoplasm induce changes in force generation and corroborate previous data showing higher levels of cell traction force for TR146 epithelial cells that have been exposed to $\mathrm{TiO}_{2}$ or $\mathrm{SiO}_{2}$ nanoparticles while migrating collectively. ${ }^{43}$

In order to reinforce the results obtained on cytoskeleton, stiffness and TFM, we finally focused our investigations on the direct adhesion properties of U251 cells by using cell adhesion assay performed at 3 time points $(15,30$ and $60 \mathrm{~min})$ on a fibronectin or hyaluronic acid coating. As expected, in the control group, the percentage of attached cells increased over time, with a maximum reaching $24.8 \%$ and $27.8 \%$ for $\mathrm{U} 251$ 


\section{A}

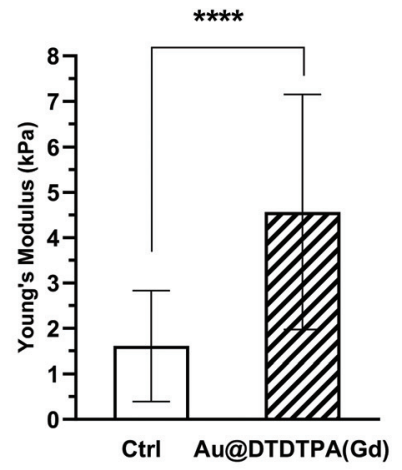

C
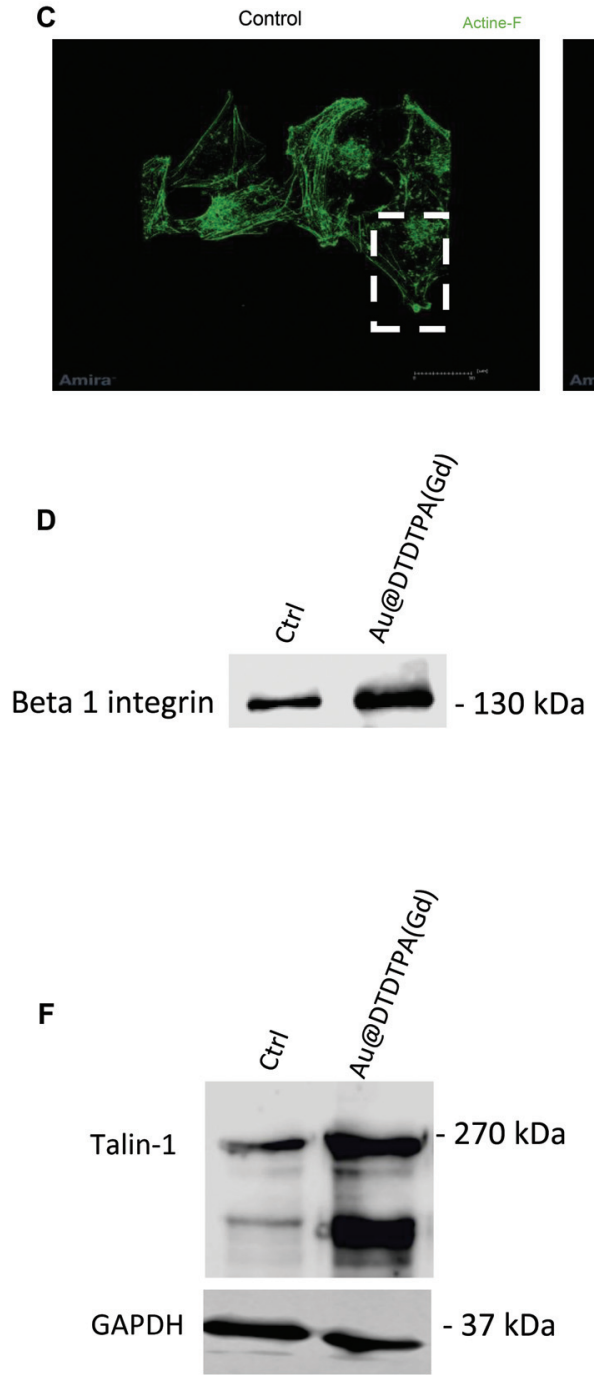

B

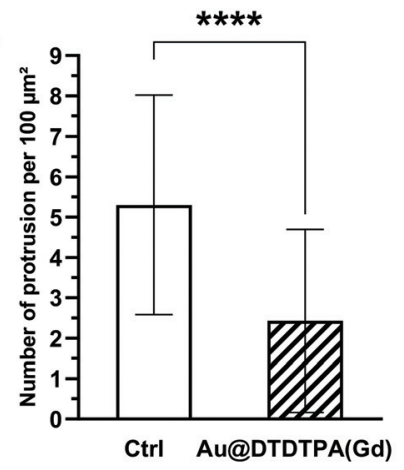

Au@DTDTPA(Gd) 5 mM
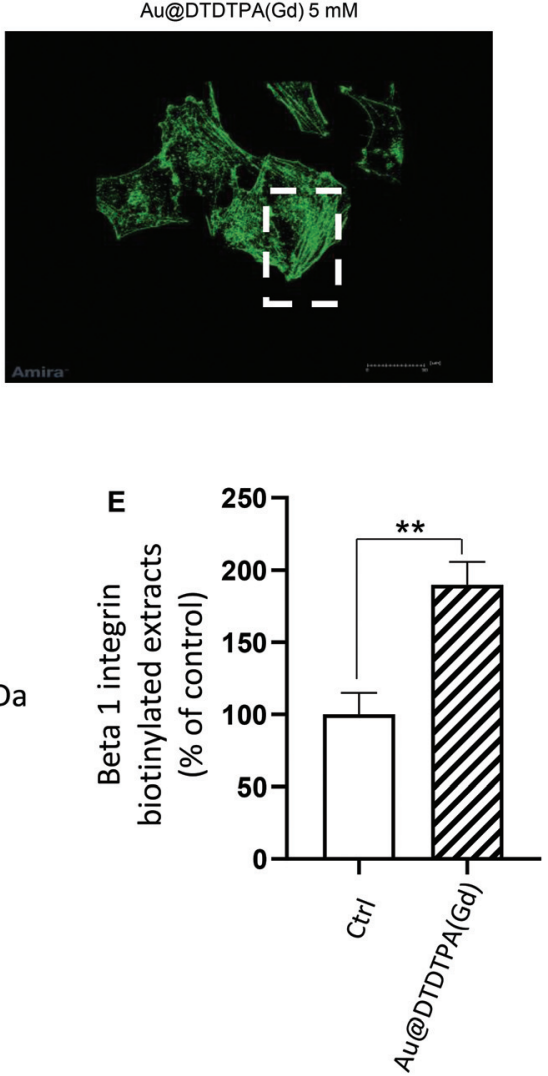

Fig. 4 Impact of Au@DTDTPA(Gd) nanoparticles on biomechanical properties and cell morphology of U251 cells. (A-B) AFM measurements were performed to assess the surface density of protrusions and the cell mechanical properties (characterized by Young's modulus) of U251 cells treated or not with Au@DTDTPA(Gd). A minimum of 50 cells for each condition were analyzed. (A) Young's modulus and (B) number of protrusions per $100 \mu \mathrm{m}^{2}$ were plotted on histograms. (C) Representative $z$-stack images of the F-actin cytoskeleton (Alexa Fluor ${ }^{\mathrm{TM}} 488$ Phalloidin) obtained by confocal microscopy. (D-E) Effect of Au(aDTDTPA(Gd) nanoparticles on the membrane Beta 1 integrin expression. (D) Cell extracts were prepared from U251 biotinylated cells treated or not with 5 mM Au@DTDTPA(Gd) nanoparticles. Expression of Beta 1 integrin localized at the cell surface was analysed by $10 \%$ SDS-PAGE followed by western blotting. (E) Expression of Beta 1 integrin was quantified by densitometry and results are representative of three independent experiments and expressed as mean \pm SD relative to the control (100\%). (F) Effect of Au@DTDTPA(Gd) nanoparticles on Talin-1 (full size) expression. Cell extracts were prepared from U251 cells treated or not with $5 \mathrm{mM}$ Au@DTDTPA(Gd) nanoparticles. Expression of Talin-1 was analysed by $10 \%$ SDS-PAGE followed by western blotting. 
A

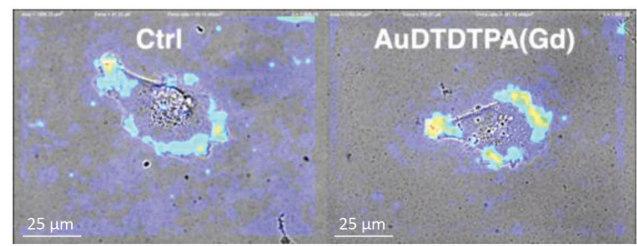

B

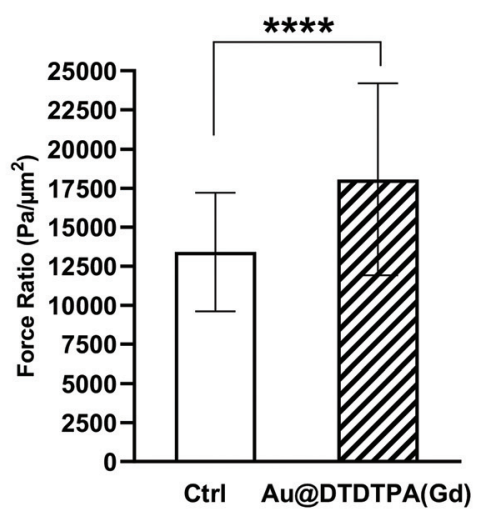

C

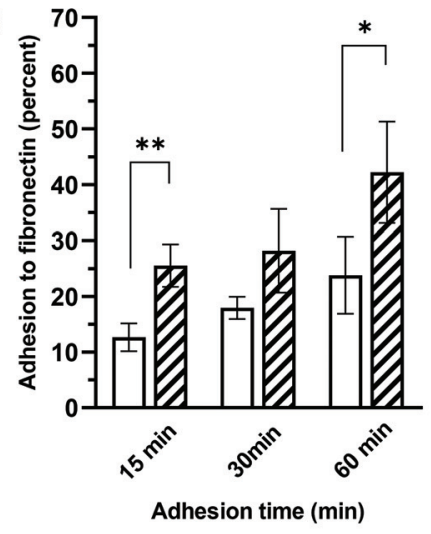

E

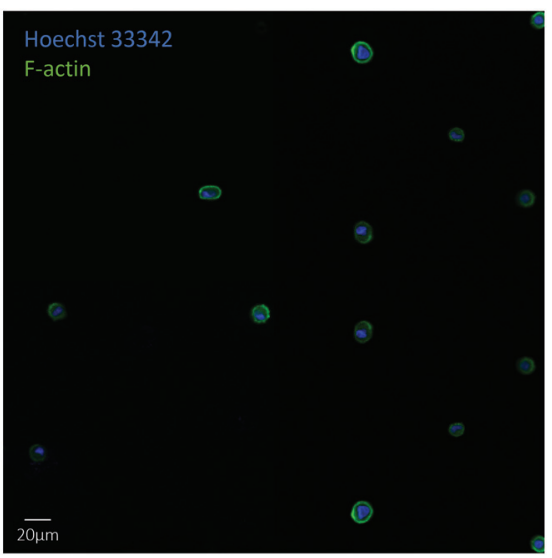

Control
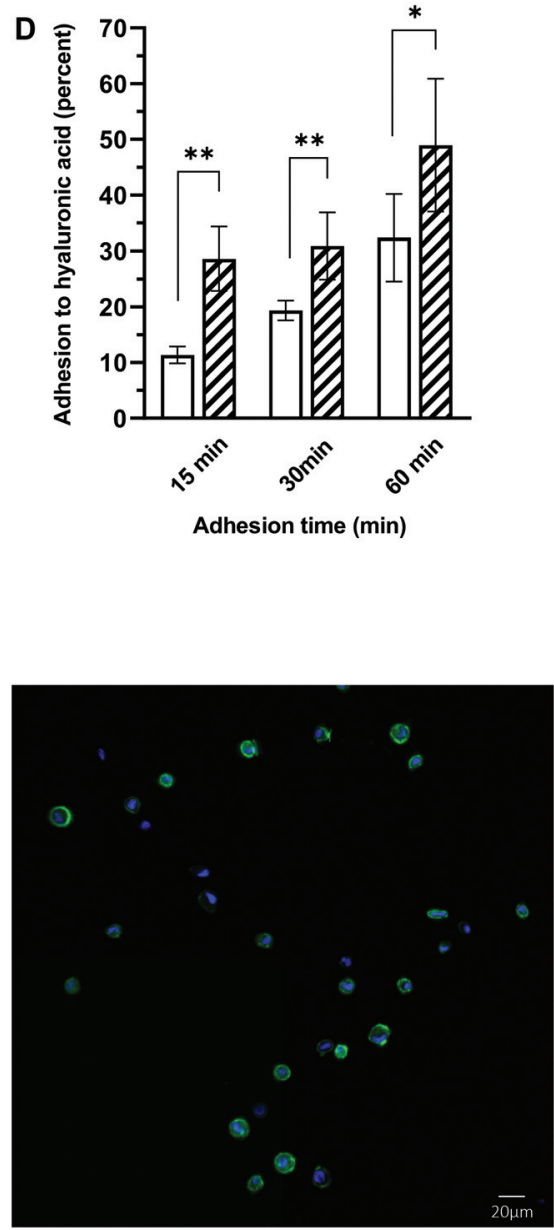

Au@DTDTPA(Gd)

Fig. 5 Impact of AuCDTDTPA(Gd) nanoparticles on traction forces and adhesion. (A) Representative snapshots of TFM analysis of single cells with the force represented as magnitude of control cells (left) and Au@DTDTPA(Gd) nanoparticle-treated cells (right) superimposed with the cell segmentation used for force integration. (B) Force ratio (in $\mathrm{pN} \mathrm{m}^{-2}$ ) corresponding to the integration of the force values over the surface obtained by the segmentation of untreated- and nanoparticle-treated U251 cells and normalized by the surface value. (C and D) After $24 \mathrm{~h}$ of exposure to 5 mM Au@DTDTPA(Gd) nanoparticles, U251 cells were exposed to Hoechst 33342 at 1/1000 during 15 minutes. Then, the cells were trypsinated and plated on 48 wells plates coated with (C) fibronectin or (D) hyaluronic acid during 15, 30 and 60 minutes. Fluorescence intensities $\left(\lambda_{\text {exc }} / \lambda_{\text {em }}: 350 / 461 \mathrm{~nm}\right.$ for Hoechst 33342) were recorded. Histograms represent the percentage of cells that have adhered after 15,30 and 60 minutes. Results are presented as mean \pm SD ( $n=7$ independent experiments). ${ }^{*} p<0.05$ and ${ }^{* *} p<0.01$ according to the Mann-Whitney $U$ test. (E) Representative images of attached cells on fibronectin-coated surface at the time point 15 min were captured for U251 cells treated or not with 5 mM Au@DTDTPA(Gd) nanoparticles (F-actin - green, cell nuclei - blue). 
plated on fibronectin and hyaluronic acid, respectively (Fig. 5C and D). Regardless of the coating and the time points, pretreatment with Au@DTDTPA(Gd) conferred a significantly higher ability to adhere to the substrate. After $15 \mathrm{~min}$ of cell incubation with the matrix coating, $25.5 \pm 1.7 \%$ of U251 cells treated with nanoparticles bind to fibronectin, compared to only $12.6 \pm 1.0 \%$ of control cells ( $p=0.0043$ ). For U251 cells exposed to nanoparticles, adhesion at $60 \mathrm{~min}$ reached $42.2 \pm$ $4.1 \%$ compared to $23.8 \pm 3.1 \%$ for control cells $(p=0.0159)$. According to the images captured after 15 minutes (Fig. 5E), the cytoskeleton appeared more developed for the Au@DTDTPA(Gd)-treated cells than for the control cells, which may explain the earlier and more important adhesion for the treated cells.

Taken together, our experiments demonstrated that Au@DTDTPA(Gd) uptake is able to counteract the migration capabilities of U251 glioma cells. These effects occur through an alteration of the intrinsic biomechanical behavior of cells that were characterized by an increase of Young's modulus, a reorganization of the actin cytoskeleton and adhesion structures, and higher traction forces. All these data are consistent with enhanced anchorage of the cells after treatment with Au@DTDTPA(Gd) nanoparticles that likely explain the diminished capacities of collective and individual migration. Such effects of metal-based nanoparticles on cell motility seem to be generalized as some of them have already been observed for other inorganic nanoparticles and other cell types. ${ }^{22,33,38,43}$ Our experiments have gone further as 3D invasion assays demonstrated that reduced motility of glioma cells also occur in a confined environment, reducing glioma invasive potential. Underlying mechanisms remain unclear and ongoing experiments are now devoted to decipher at the molecular level the action of Au@DTDTPA(Gd) nanoparticles on glioma cells.

Furthermore, Winckler's group has recently demonstrated that glioma cells emit thin ultralong membrane protrusions (called as tumor microtubes) which help them to invade and colonize healthy brain tissue and form a complex network that conveys resistance to standard tumor treatment modalities such as radiotherapy. ${ }^{4,45}$ In light of this recent knowledge, our results showing that Au@DTDTPA(Gd) nanoparticles can significantly affect the protrusion number emitted by cells appear particularly promising.

\section{Experimental section}

\section{Au@DTDTPA(Gd) nanoparticles and ICP-OES dosage of gold}

The synthesis and characterization of the Au@DTDTPA(Gd) nanoparticles were described earlier ${ }^{46,47}$ (ESI SI4 $\dagger$ ).

For a typical preparation of these gold nanoparticles, $\mathrm{HAuCl}_{4} \cdot 3 \mathrm{H}_{2} \mathrm{O}\left(200 \mathrm{mg}, 51 \times 10^{-5} \mathrm{~mol}\right)$ was placed in a $250 \mathrm{~mL}$ round-bottom flask and was dissolved with methanol $(60 \mathrm{~mL})$. In another flask, DTDTPA (256 mg, $50 \times 10^{-5} \mathrm{~mol}$ ), water $(40 \mathrm{~mL})$ and acetic acid $(2 \mathrm{~mL})$ were mixed. This solution containing DTDTPA was added to the gold salt solution under stirring. The mixture turned from yellow to orange. $\mathrm{NaBH}_{4}$
(195 mg, $\left.515 \times 10^{-5} \mathrm{~mol}\right)$ dissolved in water $(13.2 \mathrm{~mL})$ was added to the gold-DTDTPA solution under stirring at room temperature. At the beginning of $\mathrm{NaBH}_{4}$ addition, the solution first became dark brown then a black flocculate appeared. The vigorous stirring was maintained for $1 \mathrm{~h}$ before adding aqueous hydrochloric acid solution ( $2 \mathrm{~mL}, 1 \mathrm{M})$. After the partial removal of the solvent under reduced pressure the precipitate was retained on the polymer membrane and washed thoroughly and successively with $0.1 \mathrm{M}$ hydrochloric acid, water and acetone. The resulting black powder was dried (up to $200 \mathrm{mg}$ of dry powder of Au@DTDTPA) and dispersed in aqueous solution of sodium hydroxide $(\mathrm{NaOH} 0.01 \mathrm{M})$ with a final concentration of $50 \mathrm{mM}$ gold.

The functionalization of Au@DTDTPA nanoparticles by organic dyes (aminated cyanine 3, Cy3- $\mathrm{NH}_{2}$ ) was inspired from the grafting of aminated cyanine-5. ${ }^{21}$ A solution of Au@DTDTPA (9 mL, 50 mM in gold) was adjusted to pH 5. For the activation of the carboxylic groups, EDC (397 mg) and NHS (477 $\mathrm{mg})$ in deionized water $(6.48 \mathrm{~mL})$ were added to the colloid under stirring at room temperature. The agitation was maintained for $90 \mathrm{~min}$. Afterwards, the $\mathrm{pH}$ of the solution was adjusted at $\mathrm{pH} 7.5$ and $\mathrm{Cy} 3-\mathrm{NH}_{2}$ was added to the aqueous suspension of Au@DTDTPA nanoparticles. The solution was stirred for 15 minutes at room temperature and for $12 \mathrm{~h}$ at $4^{\circ} \mathrm{C}$.

After the reaction with $\mathrm{Cy} 3-\mathrm{NH}_{2}$, the nanoparticles were purified by dialysis against an acidic medium $(\mathrm{pH} 5$, Molecular Weight Cut-Off (MWCO): $6 \mathrm{kDa}$ ). The dialysis bath was changed four times $(6 \mathrm{~h}, 20 \mathrm{~h}, 26 \mathrm{~h}$, and $40 \mathrm{~h}$ after the immersion of a dialysis tube in acid aqueous solution) until it became colorless. After purification by dialysis, gold nanoparticles were concentrated by centrifugation using centrifugal concentrators (Vivaspin ${ }^{\circledR}$, MWCO: $10 \mathrm{kDa}$ ) until a gold concentration of $50 \mathrm{mM}$.

Whatever the type of nanoparticles (Au@DTDTPA or fluorescent Au@DTDTPA nanoparticles), the labeling with gadolinium ions is performed through the addition of $\mathrm{GdCl}_{3}$ to colloidal solution under stirring at room temperature. For a final gold concentration of 45-50 mM, the gadolinium concentration is $5 \mathrm{mM}$.

The titrations of gold in colloids and in the cells were performed by ICP-OES analysis. The samples were first mineralized in ultrapure aqua regia to a final concentration of at least $20 \mu \mathrm{g} \mathrm{L} \mathrm{L}^{-1}$ in gold. An ICP-OES (710 ES Varian/Agilent) with an axial torch with a concentric nebulizer and cyclonic spray chamber was used. The parameters fixed during the measurement were: power of $1.2 \mathrm{~kW}$ with argon auxiliary of $1.5 \mathrm{~L}$ $\mathrm{min}^{-1}$ and nebulizer pressure of $200 \mathrm{kPa}$. The emission lines used to measure the gold concentration were $268 \mathrm{~nm}, 243 \mathrm{~nm}$ and $208 \mathrm{~nm}$. The efficacy of the atomization is about $60 \%$ for gold. An ionizing buffer was employed for the measurements.

\section{Cell culture}

The human primary glioblastoma cell line U-251MG (Uppsala, Sweden) was obtained from American Type Culture Collection and was cultured in Dulbecco's Modified Eagle's Medium 
(DMEM) supplemented with 10\% fetal bovine serum, $0.4 \%$ L-asparagine, $0.36 \%$ L-serine, $1 \%$ L-glutamine, $1 \%$ essential amino acids, $0.5 \%$ non-essential amino acids, $0.4 \%$ vitamins, $1.25 \%$ sodium pyruvate, and $1 \%$ penicillin-streptomycin. The cells were maintained in monolayers in a tissue culture incubator at $37{ }^{\circ} \mathrm{C}$ under a $5 \% \mathrm{CO}_{2} 95 \%$ air atmosphere, and were subcultured twice a week. DMEM, amino acids, vitamins, and antibiotics were purchased from Gibco/Life Technologies (France), while other reagents were obtained from SigmaAldrich (Saint Louis, MO, USA).

Cell counting was performed using a $\mathrm{TC} 20^{\mathrm{TM}}$ automated cell counter (Bio-Rad, France) and viability assessment was performed using Trypan blue exclusion assay that allows the detection of live (unstained) and dead (stained) cells.

\section{D invasion assays}

To generate U251 spheroids, $1 \times 10^{6}$ cells were plated in $75 \mathrm{~cm}^{2}$ flasks previously coated with hydrophobic poly(2hydroxyethyl methacrylate) to prevent cell adhesion. Four days later, U251 spheroids are harvested and placed in a spinner culture flask with magnetic stirring for 10 days for growing. Then the spheroid suspension was filtered through 380 and $520 \mu \mathrm{m}$ nylon mesh filters that allowed collecting spheroids of homogeneous size $(\sim 400-500 \mu \mathrm{m})$. These spheroids were then cultured in 6-well plates coated with poly(2-hydroxyethyl methacrylate) in the presence or absence of $5 \mathrm{mM}$ Au@DTDTPA(Gd) for $24 \mathrm{~h}$. After treatment, each spheroid was placed into individual wells of a 96-well plate and then embedded with $100 \mu \mathrm{L}$ of a mixture of Matrigel ${ }^{\circledR}$ and hyaluronic acid $\left(100 \mu \mathrm{g} \mathrm{mL}{ }^{-1}\right)$. The spheroids were maintained at $37{ }^{\circ} \mathrm{C}$ in a humidified $5 \%$ $\mathrm{CO}_{2}$ atmosphere for 4 days, allowing invasion and migration processes to take place. After staining with thiazolyl blue tetrazolium bromide (MTT $1 \mathrm{mg} \mathrm{mL} \mathrm{m}^{-1}$ ), invasion of viable cells was imaged using the GelCount ${ }^{\circledR}$ system (Oxford Optronix, UK). The mean area (in $\mu \mathrm{m}^{2}$ ) and the mean distance (in $\mu \mathrm{m}$ ) of invasion from at least 34 independent spheroids (6 independent experiments) were quantified using Image $\mathrm{J}$ and GelCount ${ }^{\circledR}$ Software. Initial and final surface (in $\mu \mathrm{m}^{2}$ ) of at least 19 independent spheroids (3 independent experiments) were quantified using Image $\mathrm{J}$.

\section{Wound healing assay}

U251 glioblastoma cells were seeded at a concentration of 2.5 $\times 10^{5}$ cells per well in a 6-well plate containing Dulbecco's modified Eagle's medium supplemented with $10 \%$ fetal bovine serum (FBS) and incubated for $24 \mathrm{~h}$ at $37{ }^{\circ} \mathrm{C}$ under a humidified $5 \% \mathrm{CO}_{2}$ atmosphere. After attachment of the cells to the plate, the cells were treated with $5 \mathrm{mM}$ Au@DTDTPA (Gd) nanoparticles for $24 \mathrm{~h}$. When the nanoparticles were removed, a scratch was created into the confluent monolayer of U251 cells using a sterile p1000 pipet tip. The cells were then replaced into the incubator for $16 \mathrm{~h}$. Three representative images of each scratch area were captured at $0 \mathrm{~h}$ (just after scratching cells) and $16 \mathrm{~h}$ after incubation using a transmitted-light microscope (Nikon DIAPHOT 300 equipped with digital camera Nikon Digital sight-DS-Fi1) (40× magnification).
The plugin "MRI Wound Healing Tool" from ImageJ helped us to determine the area of the gaps for each image. As an indicator of the collective migration ability, the wound healing rate was calculated as follows: $\left(\right.$ Area $\left._{0} \mathrm{~h}-\mathrm{Area}_{16 \mathrm{~h}}\right) / \mathrm{Area}_{0 \mathrm{~h}} \times 100$.

\section{Cell tracking by time-lapse video microscopy imaging}

U251 cells $\left(1 \times 10^{4}\right)$ seeded on a fibronectin-coated 24-well plate were allowed to attach to the substrate and treated with 5 mM Au@DTDTPA(Gd) nanoparticles during 24 h. Before imaging, cells were treated with $1 \mu \mathrm{g} \mathrm{mL} \mathrm{m}^{-1}$ mitomycin $\mathrm{C}$ for $2 \mathrm{~h}$ to inhibit cell proliferation. The cells were then PBSwashed and fresh medium was added. The cells were maintained at $37{ }^{\circ} \mathrm{C}$ under a $5 \% \mathrm{CO}_{2}$ atmosphere in a temperaturecontrolled chamber (PECON) and then observed under a 20× magnification objective during $24 \mathrm{~h}$ using a Zeiss Axio Observer (Carl Zeiss MicroImaging GmbH, Germany). Data were acquired using the MetaMorph software (Roper Scientific). Cell velocity, distance and directional persistence analyses were computed using ImageJ software (National Institutes of Health, Bethesda, MD, USA). For each condition, 48 randomly chosen cells have been tracked.

\section{Atomic force microscopy imaging}

Prior to AFM analyses, $5 \times 10^{5}$ U251 cells were seeded onto $50 \mathrm{~mm}$ Willco-dish ${ }^{\circledR}$ pre-coated with $10 \mu \mathrm{g} \mathrm{mL} \mathrm{m}^{-1}$ fibronectin. On the next day, the cells were treated with $5 \mathrm{mM}$ Au@DTDTPA(Gd) nanoparticles during $24 \mathrm{~h}$. The cells were washed with PBS before adding $2 \mathrm{~mL}$ of medium. Then, AFM measurements were performed with a BioScope Catalyst ${ }^{\mathrm{TM}}$ (Bruker, Billerica, USA) mounted on a Nikon Eclipse Ti inverted microscope (Nikon, Tokyo, Japan) and operated in the PFQNM mode to acquire topographical and mechanical images of live cells. This mode has proved itself to allow higher resolution at a faster acquisition speed (similar to tapping mode imaging) than the classical Force-Volume measurements. Preliminary experiments have been conducted using SCANASYST-AIR probes (Bruker, Billerica, USA) having a nominal spring constant of $0.4 \mathrm{~N} \mathrm{~m}^{-1}$ and a resonance frequency of $\sim 70 \mathrm{kHz}$ but generally speaking, the cantilever was too stiff for this type of cells. This prompted us to utilize PFQNM-LC-A-CAL probes (Bruker, Billerica, USA), having a nominal spring constant of $0.1 \mathrm{~N} \mathrm{~m}^{-1}$ and a resonance frequency of $\sim 45 \mathrm{kHz}$, the tips being calibrated as previously described. The tip geometry ("ace of spades" pyramidal shape, with a tip height of $17 \mu \mathrm{m}$ and an apex diameter of approximately $130 \mathrm{~nm}$ ) is designed on purpose to minimize the viscous drag during imaging in liquids. For PFQNM experiments, we used a PeakForce frequency of $0.25 \mathrm{kHz}$ in order to maximize the contact time between the tip and the sample (and also collect more than one force curve per pixel), and a PeakForce amplitude of $1 \mu \mathrm{m}$ to optimize tracking since the cells are quite high (up to $7 \mu \mathrm{m}$ ). Images were captured in the culture medium at a resolution of 256 or 128 pixels per line, at $37{ }^{\circ} \mathrm{C}$ using a Perfusing Stage Incubator (Bruker, Billerica, USA). The Petri dish was put on the baseplate when the temperature set point was reached and stabilized over time (a 
Lakeshore temperature controller was used). Young's modulus, step height, surface and volume measurements were calculated using NanoscopeAnalysis (Bruker, Billerica, USA). In the present study, only the surface density of protrusions and the cells mechanical properties were considered. With respect to Young's modulus calculations, for each type of cells, 10 different cell dishes coming from the same culture were analyzed one after the other (each dish has never been handled more than $3 \mathrm{~h}$ ) and the experiments were triplicated to draw a reliable conclusion. Overall, a minimum of 50 cells for each condition (with and without NP incubation) were analyzed. Considering both the indentation depth of the tip given by the deformation channel and the cell height given by the cross sections achieved on height images at the same locations, Young's modulus was exclusively calculated in areas where the cell height was at least 3 times superior to the indentation depth, in order to avoid any influence of the substrate on the measured values. Thus, perinuclear areas were avoided. The Sneddon model was used to estimate the interaction between the tip and the substrate. In order to avoid mechanical stress to the cells, the loading force was adjusted between a few tens up to a few hundreds of piconewtons. The force curves were extracted from the chosen area from the PFQNM images using the Peak Force Capture option of the Nanoscope software. For the topographical AFM measurements (more in particular the cell protrusions), a minimum of 50 images were processed for each condition.

\section{Immunocytofluorescence}

U251 cells were plated at the density $5 \times 10^{3}$ cells per well in 8-well Labtek II coated with $10 \mu \mathrm{g} \mathrm{mL}{ }^{-1}$ of fibronectin for one day. The cells were exposed to $5 \mathrm{mM}$ Au@DTDTPA(Gd) for $24 \mathrm{~h}$. The cells were fixed with PFA $4 \%$ for $30 \mathrm{~min}$, then gently washed three times with PBS. To visualize F-actin distribution, slides were incubated for $45 \mathrm{~min}$ with Alexafluor-488-conjugated phalloidin (Ab176753, Abcam) diluted 1/1000 in PBS with $2 \%(\mathrm{w} / \mathrm{v})$ BSA. The cells were then washed three times with PBS. Immunofluorescence-labeled cell preparations were analyzed using a Zeiss LSM 710 confocal laser scanning microscope with the $63 \times$ oil-immersion objective zoom $1 \times$ and Zeiss operating system (Carl Zeiss MicroImaging $\mathrm{GmbH}$, Deutschland). Acquisitions were performed by exciting Alexafluor 488 with Argon laser. Emitted fluorescence was detected through the appropriate wavelength window. Twenty images were captured with a $0.25 \mu \mathrm{m} z$-step.

\section{Confocal and STED microscopy}

Confocal and STED microscopy on immunostained U251 cells were performed using the STEDYCON (Abberior Instruments $\mathrm{GmbH}$ ). Confocal microscopy was performed under pulsed excitation of Сy3 and Abberior STAR RED at $561 \mathrm{~nm}$ and $640 \mathrm{~nm}$ respectively, on samples mounted on a Abberior mount liquid antifade (Abberior $\mathrm{GmbH}$ ). STED depletion was performed using a pulsed $775 \mathrm{~nm}$ laser source. Image processing and analysis were performed using Image $\mathrm{J}$.
Due to the high concentration of metallic nanoparticles in cells, STED observation could occasionally prove to be very difficult and the use of high STED laser powers was precluded. ${ }^{48}$ However, we managed to obtain comparison of STED and confocal on cells or cell regions at resolution of $<80 \mathrm{~nm}$ (and down to $50 \mathrm{~nm}$ ) (Fig. 1).

\section{Proteins extraction and western-blot analysis}

Whole-cell extracts were prepared as previously described. ${ }^{49}$ Briefly, whole-cell extracts were prepared by scraping cells in ice-cold lysis buffer (10 mM Tris- $\mathrm{HCl}, \mathrm{pH}$ 7.5, $150 \mathrm{mM} \mathrm{NaCl}$, $5 \mathrm{mM}$ EDTA, 1\% Triton X-100, and proteinase inhibitor cocktail).

Cell surface protein isolation was performed as previously described. ${ }^{49}$ After washing, the cell surface proteins were biotinylated with PBS containing $0.5 \mu \mathrm{g} \mathrm{mL} \mathrm{m}^{-1}$ of EZ-Link sulfoNHS-LC-biotin (Thermofisher) for $30 \mathrm{~min}$ at $4{ }^{\circ} \mathrm{C}$. After three washes, the cells were incubated with $100 \mathrm{mM}$ glycine for $30 \mathrm{~min}$ at $4{ }^{\circ} \mathrm{C}$ in order to limit nonspecific binding. The cells were washed three times in ice-cold lysis buffer before protein extraction. Solubilized biotinylated proteins were then affinity purified using $40 \mu \mathrm{L}$ of monomeric avidin-agarose beads (GE Healthcare, Chicago, IL, USA) incubated with $120 \mu \mathrm{g}$ of biotinylated proteins. Incubation was performed overnight at $4{ }^{\circ} \mathrm{C}$ under gentle orbital agitation ( $5 \mathrm{rpm})$, and then followed by five washes in lysis buffer.

The protein concentrations in whole-cell extracts and membrane extracts were quantified by the Bradford method (BioRad Laboratories, Marne-la-Vallée, France). Proteins were separated by sodium dodecyl sulfate-polyacrylamide gel electrophoresis, transferred onto a nitrocellulose membrane (Schleicher \& Schuell GmbH, Mantes la Ville, France), and incubated overnight at $4{ }^{\circ} \mathrm{C}$ with primary antibodies. Immunoreactive bands were revealed using an ECL Plus chemiluminescence kit from Amersham Biosciences (Orsay, France). GAPDH was used as a control to ensure equal loading.

\section{Traction force microscopy}

TFM requires three distinct procedures: (1) cells are plated on an elastic substrate containing fiducial markers allowing the quantification of gel deformation visually, for instance fluorescent beads or quantum dots. (2) A discrete gel displacement caused by adherent cells is calculated by tracking fluorescent beads movements. The most common techniques for tracking are particle image velocimetry (PIV) and particle tracking velocimetry (PTV). (3) Finally, the traction force field $\mathrm{f}$ is calculated from the displacement field by making use of a mechanical model of the elastic substrate. ${ }^{50}$

Polyacrylamide gel coated coverslips were prepared at a 17 $\mathrm{kPa}$ modulus as previously described, ${ }^{51}$ using the following specific conditions: $1.5 \times 10^{5} \mathrm{U} 251$ cells were then seeded before adding 1 mM Au@DTDTPA(Gd)-Cy3 during $24 \mathrm{~h}$.

The cells were washed twice and then observed under a $63 \times$ objective using a Zeiss Axio Observer (Carl Zeiss MicroImaging $\mathrm{GmbH}$ ) and a CoolSNAP HQ (Roper Scientific, France) camera. Image acquisitions were performed every $5 \mathrm{~min}$ during 
3 hours and beads displacement was analyzed using the JEasyTFM plugin running under ImageJ.

\section{Cell adhesion assay}

$6 \times 10^{4}$ U251 cells per $\mathrm{mL}$ were plated in $25 \mathrm{~cm}^{2}$ flasks for 3 days. Then, tumor cells were treated with $5 \mathrm{mM}$ Au@DTDTPA (Gd) for $24 \mathrm{~h}$. In parallel, 48-well plates were pre-treated with $10 \mu \mathrm{g} \mathrm{ml} \mathrm{m}^{-1}$ of fibronectin or with $10 \mu \mathrm{g} \mathrm{ml}^{-1}$ hyaluronic acid in HBSS for $1 \mathrm{~h}$ at $37^{\circ} \mathrm{C}$ and then dried overnight at $4{ }^{\circ} \mathrm{C}$. Control or treated tumor cells were then stained with $1 \mathrm{~mL}$ Hoechst $33342(20 \mu \mathrm{M}$ in HBSS, Thermo Scientific, 62249) for $30 \mathrm{~min}$ at $37^{\circ} \mathrm{C}$ and harvested. $1 \times 10^{5}$ stained cells per well were added on the pre-coated P48 plates. After 15, 30, and 60 min of incubation at $37{ }^{\circ} \mathrm{C}$ under a humidified $5 \% \mathrm{CO}_{2}$ atmosphere, the cells were gently washed once with HBSS.

Measurement of attached cells after 15, 30, and $60 \mathrm{~min}$. Washed cells were lysed with DMSO 100\%. Quantification of fluorescence intensity of cell lysates $\left(\lambda_{\text {exc }} / \lambda_{\mathrm{em}}: 350 \mathrm{~nm} / 461 \mathrm{~nm}\right)$ with a Tecan Infinite 200 microplate reader (Infinite M200 pro, Tecan $^{\mathrm{TM}}$ ) allowed assessing the attached cells for 7 independent experiments, each condition was realized in duplicate. To quantify the fluorescence at $0 \mathrm{~min}, 1 \times 10^{5}$ stained cells were transferred in $1.5 \mathrm{~mL}$ Eppendorf tubes, then centrifuged at $300 \mathrm{G}$ during $10 \mathrm{~min}$ at $20^{\circ} \mathrm{C}$. The supernatants were removed, and then the stained cells were lysed with DMSO $100 \%$.

F-actin cytoskeleton of attached cells after 15 min. Au@DTDTPA(Gd) treatment and cell adhesion assay were conducted as previously described using Lab-Tek ${ }^{\mathrm{TM}}$ II Chamber Slide ${ }^{\mathrm{TM}} 8$ wells coated with $10 \mu \mathrm{g} \mathrm{mL}^{-1}$ of fibronectin. $5 \times 10^{4}$ stained U251 cells were plated and after $15 \mathrm{~min}$ at $37^{\circ} \mathrm{C}$ in a humidified $5 \% \mathrm{CO}_{2}$ atmosphere, the cells were gently washed once with HBSS. The cells were fixed with PFA 4\% during $30 \mathrm{~min}$, and then gently washed once with PBS. F-Actin staining was performed using Alexafluor-488-conjugated phalloidin (Ab176753, Abcam) diluted 1/1000 in PBS with 2\% (w/v) BSA. Phalloidin fluorescence was analyzed using an ImageXpress ${ }^{\circledR}$ Micro Confocal device with $10 \times$ Plan APO objective and MetaXpress Software (Molecular Devices, Sunnyvale, CA). Acquisitions were performed by exciting Alexafluor 488 . Emitted fluorescence was detected through the appropriate wavelength window. Ten images were captured with a $1 \mu \mathrm{m}$ $z$-step.

\section{Statistical analysis}

The Mann-Whitney $U$ test was used to compare untreated and treated groups. A $P$-value less than 0.05 was considered as statistically significant.

\section{Conclusion}

Over the last decade, Roux et al. have developed the $\mathrm{Au} @ D T D T P A(G d)$ nanoparticles, i.e. original ultrasmall nanoparticles composed of a gold core and dithiolated polyaminocarboxylate shell doped with $\sim 50$ gadolinium ions, and demonstrated their relevance and their potential for MRI- guided radiation therapy. ${ }^{46,47}$ In particular, preclinical experiments demonstrated that Au@DTDTPA(Gd) could be of interest for the management of brain tumor. ${ }^{5}$

In the present work, exposure of U251 glioma cells to Au@DTDTPA(Gd) led to high accumulation of gold nanoparticles, that were mainly diffusely distributed in the cytoplasm of the tumor cells. Our results showed no direct in vitro cytotoxicity, and U251 cell proliferation was not altered. By contrast, our experiments pointed out a noticeable decrease in glioma cell invasiveness when tumor cells were exposed to Au@DTDTPA(Gd) nanoparticles. As the proteolysis activities were not directly affected by the intracytoplasmic accumulation of nanoparticles under our experimental conditions, the antiinvasive effect cannot be attributed to a matrix remodeling impairment. Instead, Au@DTDTPA(Gd) nanoparticles affected the intrinsic biomechanical properties of U251 glioma cells, such as cell stiffness, adhesion and generated traction forces, and significantly reduced the formation of protrusions, thus exerting an inhibitory effect on their migration capacities.

While initially developed for combining with radiation therapy, the Au@DTDTPA(Gd) nanoparticles could have huge interest for therapeutic management of astrocytic tumors, not only as an radio-enhancing agent but also by reducing invasive potential of glioma cells. Indeed, it is well-established that migrating/invading glioblastoma cells preserve their stem-like properties with maintained tumorigenic potential ${ }^{52}$ which makes anti-invasive strategies become a priority. ${ }^{53,54}$

\section{Conflicts of interest}

The authors declare no competing financial interests.

\section{Author contributions}

M. Durand, E. Lelievre, A. Chateau, L. Chazee \& J. Jubreaux: in vitro biological experiments and data analysis. A. Berquand: AFM experiments and data analysis. G. Laurent, S. Roux \& R. Bazzi: synthesis and characterization of nanoparticles. F. Eghiaian: STED microscopy experiments and data analysis. P. Carl \& P. Ronde: traction force microscopy experiments and data analysis. M. Barberi-Heyob \& P. Chastagner: scientific \& clinical discussion. J. Devy \& S. Pinel: project management and coordination, data analysis and manuscript redaction.

\section{Acknowledgements}

This work was supported by the research funds of (i) the Cancéropole Est, Régions Grand Est and Bourgogne-FrancheComté, (ii) Ligue Contre le Cancer CCIR-GE, and (iii) the CPER. We would like to thank Adrien Dos Santos for his help for the graphical abstract. The authors thank Dr Christine Terryn of the PICT platform for technical assistance in imaging. 


\section{References}

1 M. Alieva, V. Leidgens, M. J. Riemenschneider, C. A. Klein, P. Hau and J. van Rheenen, Intravital Imaging of Glioma Border Morphology Reveals Distinctive Cellular Dynamics and Contribution to Tumor Cell Invasion, Sci. Rep., 2019, 9, 2054, DOI: 10.1038/s41598-019-38625-4.

2 S. Pinel, N. Thomas, C. Boura and M. Barberi-Heyob, Approaches to Physical Stimulation of Metallic Nanoparticles for Glioblastoma Treatment, Adv. Drug Delivery Rev., 2019, 138, 344-357, DOI: 10.1016/j. addr.2018.10.013.

3 C. Alric, I. Miladi, D. Kryza, J. Taleb, F. Lux, R. Bazzi, C. Billotey, M. Janier, P. Perriat, S. Roux and O. Tillement, The Biodistribution of Gold Nanoparticles Designed for Renal Clearance, Nanoscale, 2013, 5(13), 5930-5939, DOI: 10.1039/C3NR00012E.

4 S. J. McMahon, W. B. Hyland, M. F. Muir, J. A. Coulter, S. Jain, K. T. Butterworth, G. Schettino, G. R. Dickson, A. R. Hounsell, J. M. O'Sullivan, K. M. Prise, D. G. Hirst and F. J. Currell, Biological Consequences of Nanoscale Energy Deposition near Irradiated Heavy Atom Nanoparticles, Sci. Rep., 2011, 1, 18, DOI: 10.1038/ srep00018.

5 I. Miladi, C. Alric, S. Dufort, P. Mowat, A. Dutour, C. Mandon, G. Laurent, E. Bräuer-Krisch, N. Herath, J.-L. Coll, M. Dutreix, F. Lux, R. Bazzi, C. Billotey, M. Janier, P. Perriat, G. L. Duc, S. Roux and O. Tillement, The In Vivo Radiosensitizing Effect of Gold Nanoparticles Based MRI Contrast Agents, Small, 2014, 10(6), 1116-1124, DOI: 10.1002/smll.201302303.

6 N. Pernodet, X. Fang, Y. Sun, A. Bakhtina, A. Ramakrishnan, J. Sokolov, A. Ulman and M. Rafailovich, Adverse Effects of Citrate/Gold Nanoparticles on Human Dermal Fibroblasts, Small, 2006, 2(6), 766-773, DOI: 10.1002/smll.200500492.

7 R. R. Arvizo, S. Saha, E. Wang, J. D. Robertson, R. Bhattacharya and P. Mukherjee, Inhibition of Tumor Growth and Metastasis by a Self-Therapeutic Nanoparticle, Proc. Natl. Acad. Sci. U. S. A., 2013, 110(17), 6700-6705, DOI: $10.1073 /$ pnas.1214547110.

8 W. Li, X. Li, S. Liu, W. Yang, F. Pan, X.-Y. Yang, B. Du, L. Qin and Y. Pan, Gold Nanoparticles Attenuate Metastasis by Tumor Vasculature Normalization and EpithelialMesenchymal Transition Inhibition, Int. J. Nanomed., 2017, 12, 3509, DOI: 10.2147/IJN.S128802.

9 B. D. Chithrani, A. A. Ghazani and W. C. W. Chan, Determining the Size and Shape Dependence of Gold Nanoparticle Uptake into Mammalian Cells, Nano Lett., 2006, 6(4), 662-668, DOI: 10.1021/nl052396o.

10 B. D. Chithrani and W. C. W. Chan, Elucidating the Mechanism of Cellular Uptake and Removal of ProteinCoated Gold Nanoparticles of Different Sizes and Shapes, Nano Lett., 2007, 7(6), 1542-1550, DOI: 10.1021/nl070363y.

11 K. Huang, H. Ma, J. Liu, S. Huo, A. Kumar, T. Wei, X. Zhang, S. Jin, Y. Gan, P. C. Wang, S. He, X. Zhang and
X.-J. Liang, Size-Dependent Localization and Penetration of Ultrasmall Gold Nanoparticles in Cancer Cells, Multicellular Spheroids, and Tumors in Vivo, ACS Nano, 2012, 6(5), 4483, DOI: 10.1021/nn301282m.

12 W. Jiang, B. Y. S. Kim, J. T. Rutka and W. C. W. Chan, Nanoparticle-Mediated Cellular Response Is SizeDependent, Nat. Nanotechnol., 2008, 3(3), 145-150, DOI: 10.1038/nnano.2008.30.

13 D. B. Chithrani, S. Jelveh, F. Jalali, M. van Prooijen, C. Allen, R. G. Bristow, R. P. Hill and D. A. Jaffray, Gold Nanoparticles as Radiation Sensitizers in Cancer Therapy, Radiat. Res., 2010, 173(6), 719-728, DOI: 10.1667/RR1984.1.

14 C. Boyoglu, Q. He, G. Willing, S. Boyoglu-Barnum, V. A. Dennis, S. Pillai and S. R. Singh, Microscopic Studies of Various Sizes of Gold Nanoparticles and Their Cellular Localizations https://www.hindawi.com/journals/isrn/2013/ 123838/(accessed Sep 21, 2020). DOI:DOI: 10.1155/2013/ 123838.

15 S.-M. Chuang, Y.-H. Lee, R.-Y. Liang, G.-D. Roam, Z.-M. Zeng, H.-F. Tu, S.-K. Wang and P. J. Chueh, Extensive Evaluations of the Cytotoxic Effects of Gold Nanoparticles, Biochim. Biophys. Acta, Gen. Subj., 2013, 1830(10), 49604973, DOI: 10.1016/j.bbagen.2013.06.025.

16 Q. Xia, J. Huang, Q. Feng, X. Chen, X. Liu, X. Li, T. Zhang, S. Xiao, H. Li, Z. Zhong and K. Xiao, Size- and Cell TypeDependent Cellular Uptake, Cytotoxicity and in Vivo Distribution of Gold Nanoparticles, Int. J. Nanomed., 2019, 14, 6957, DOI: 10.2147/IJN.S214008.

17 Y. Hou, K. Cai, J. Li, X. Chen, M. Lai, Y. Hu, Z. Luo, X. Ding and D. Xu, Effects of Titanium Nanoparticles on Adhesion, Migration, Proliferation, and Differentiation of Mesenchymal Stem Cells, Int. J. Nanomed., 2013, 8, 3619, DOI: $10.2147 / \mathrm{IJN} . S 38992$.

18 A. Fayzullin, C. J. Sandberg, M. Spreadbury, B. M. Saberniak, Z. Grieg, E. Skaga, I. A. Langmoen and E. O. Vik-Mo, Phenotypic and Expressional Heterogeneity in the Invasive Glioma Cells, Transl. Oncol., 2019, 12(1), 122, DOI: 10.1016/j.tranon.2018.09.014.

19 M. Vinci, C. Box and S. A. Eccles, Three-Dimensional (3D) Tumor Spheroid Invasion Assay, J. Vis. Exp., 2015, 99, e52686, DOI: 10.3791/52686.

20 K. M. Tevis, Y. L. Colson and M. W. Grinstaff, Embedded Spheroids as Models of the Cancer Microenvironment, Adv. Biosyst., 2017, 1(10), 1700083, DOI: 10.1002/ adbi.201700083.

21 G. Jiménez Sánchez, P. Maury, L. Stefancikova, O. Campion, G. Laurent, A. Chateau, F. Bouraleh Hoch, F. Boschetti, F. Denat, S. Pinel, J. Devy, E. Porcel, S. Lacombe, R. Bazzi and S. Roux, Fluorescent Radiosensitizing Gold Nanoparticles, Int. J. Mol. Sci., 2019, 20(18), 4618, DOI: 10.3390/ijms20184618.

22 T. Zhou, M. Yu, B. Zhang, L. Wang, X. Wu, H. Zhou, Y. Du, J. Hao, Y. Tu, C. Chen and T. Wei, Inhibition of Cancer Cell Migration by Gold Nanorods: Molecular Mechanisms and Implications for Cancer Therapy, Adv. Funct. Mater., 2014, 24(44), 6922-6932, DOI: 10.1002/adfm.201401642. 
23 S.-S. Shin, D.-H. Noh, B. Hwang, J.-W. Lee, S. L. Park, S.-S. Park, B. Moon, W.-J. Kim and S.-K. Moon, Inhibitory Effect of Au@Pt-NSs on Proliferation, Migration, and Invasion of EJ Bladder Carcinoma Cells: Involvement of Cell Cycle Regulators, Signaling Pathways, and Transcription Factor-Mediated MMP-9 Expression, Int. J. Nanomed., 2018, 13, 3295, DOI: 10.2147/IJN.S158463.

24 V. A. Cuddapah, S. Robel, S. Watkins and H. Sontheimer, A Neurocentric Perspective on Glioma Invasion, Nat. Rev. Neurosci., 2014, 15(7), 455, DOI: 10.1038/nrn3765.

25 M. W. Roomi, T. Kalinovsky, A. Niedzwiecki and M. Rath, Modulation of UPA, MMPs and Their Inhibitors by a Novel Nutrient Mixture in Human Glioblastoma Cell Lines, Int. J. Oncol., 2014, 45(2), 887-894, DOI: 10.3892/ ijo.2014.2465.

26 P. A. Forsyth, H. Wong, T. D. Laing, N. B. Rewcastle, D. G. Morris, H. Muzik, K. J. Leco, R. N. Johnston, P. M. A. Brasher, G. Sutherland and D. R. Edwards, Gelatinase-A (MMP-2), Gelatinase-B (MMP-9) and Membrane Type Matrix Metalloproteinase-1 (MT1-MMP) Are Involved in Different Aspects of the Pathophysiology of Malignant Gliomas, Br. J. Cancer, 1999, 79(11-12), 1828, DOI: $10.1038 /$ sj.bjc.6990291.

27 F. Liu, D. Ma, W. Chen, X. Chen, Y. Qian, Y. Zhao, T. Hu, R. Yin, Y. Zhu, Y. Zhang, Y. Zhang and W. Zhao, Gold Nanoparticles Suppressed Proliferation, Migration, and Invasion in Papillary Thyroid Carcinoma Cells via Downregulation of CCT3 https://www.hindawi.com/journals/jnm/2019/1687340/ (accessed Sep 21, 2020). DOI:DOI: 10.1155/2019/1687340.

28 C. Hagemann, J. Anacker, R.-I. Ernestus and G. H. Vince, A Complete Compilation of Matrix Metalloproteinase Expression in Human Malignant Gliomas, World J. Cancer Res, 2012, 3(5), 67, DOI: 10.5306/wjco.v3.i5.67.

29 J. S. Rao, Molecular Mechanisms of Glioma Invasiveness: The Role of Proteases, Nat. Rev. Cancer, 2003, 3(7), 489501, DOI: $10.1038 /$ nrc1121.

30 P. Friedl and K. Wolf, Tumour-Cell Invasion and Migration: Diversity and Escape Mechanisms, Nat. Rev. Cancer, 2003, 3(5), 362-374, DOI: 10.1038/nrc1075.

31 J. E. N. Jonkman, J. A. Cathcart, F. Xu, M. E. Bartolini, J. E. Amon, K. M. Stevens and P. Colarusso, An Introduction to the Wound Healing Assay Using Live-Cell Microscopy, Cell Adh. Migr., 2014, 8(5), 440-451, DOI: 10.4161/cam.36224.

32 P. Jain, R. A. Worthylake and S. K. Alahari, Quantitative Analysis of Random Migration of Cells Using Time-Lapse Video Microscopy, J. Vis. Exp., 2012, 63, e3585, DOI: $10.3791 / 3585$.

33 L. Li, W. Zhang, V. D. D. Seshadri and G. Cao, Synthesis and Characterization of Gold Nanoparticles from Marsdenia Tenacissima and Its Anticancer Activity of Liver Cancer HepG2 Cells, Artif. Cells, Nanomed., Biotechnol., 2019, 47(1), 3029-3036, DOI: 10.1080/21691401.2019.1642902.

34 E. Shahhoseini, B. N. Feltis, M. Nakayama, T. J. Piva, D. Pouniotis, S. S. Alghamdi and M. Geso, Combined
Effects of Gold Nanoparticles and Ionizing Radiation on Human Prostate and Lung Cancer Cell Migration, Int. J. Mol. Sci., 2019, 20(18), 4488, DOI: 10.3390/ ijms20184488.

$35 \mathrm{~J} . \mathrm{Xu}, \mathrm{N}$. Galvanetto, J. Nie, Y. Yang and V. Torre, Rac1 Promotes Cell Motility by Controlling Cell Mechanics in Human Glioblastoma, Cancer, 2020, 12(6), 1667, DOI: 10.3390/cancers12061667.

36 B. Pontes, P. Monzo, L. Gole, A.-L. Le Roux, A. J. Kosmalska, Z. Y. Tam, W. Luo, S. Kan, V. Viasnoff, P. Roca-Cusachs, L. Tucker-Kellogg and N. C. Gauthier, Membrane Tension Controls Adhesion Positioning at the Leading Edge of Cells, J. Cell Biol., 2017, 216(9), 2959-2977, DOI: $10.1083 /$ jcb.201611117.

37 D. Septiadi, F. Crippa, T. L. Moore, B. Rothen-Rutishauser and A. Petri-Fink, Nanoparticle-Cell Interaction: A Cell Mechanics Perspective, Adv. Mater., 2018, 30(19), 1704463, DOI: 10.1002/adma.201704463.

38 V. Mulens-Arias, A. Balfourier, A. Nicolás-Boluda, F. Carn and F. Gazeau, Disturbance of Adhesomes by Gold Nanoparticles Reveals a Size- and Cell Type-Bias, Biomater. Sci., 2018, 7(1), 389-408, DOI: 10.1039/C8BM01267A.

39 K.-P. Fang, J.-L. Zhang, Y.-H. Ren and Y.-B. Qian, Talin-1 Correlates with Reduced Invasion and Migration in Human Hepatocellular Carcinoma Cells, Asian Pac. J. Cancer Prev., 2014, 15(6), 2655-2661, DOI: 10.7314/apjcp.2014.15.6.2655.

40 C. M. Kraning-Rush, J. P. Califano and C. A. Reinhart-King, Cellular Traction Stresses Increase with Increasing Metastatic Potential, PLoS One, 2012, 7(2), e32572, DOI: 10.1371/journal.pone.0032572.

41 S. V. Plotnikov, B. Sabass, U. S. Schwarz and C. M. Waterman, High-Resolution Traction Force Microscopy, Methods Cell Biol., 2014, 123, 367-394, DOI: 10.1016/B978-0-12-420138-5.00020-3.

42 K. Tanner, Perspective: The Role of Mechanobiology in the Etiology of Brain Metastasis, APL Bioeng., 2018, 2(3), 031801, DOI: 10.1063/1.5024394.

43 C. Y. Tay, P. Cai, M. I. Setyawati, W. Fang, L. P. Tan, C. H. L. Hong, X. Chen and D. T. Leong, Nanoparticles Strengthen Intracellular Tension and Retard Cellular Migration, Nano Lett., 2014, 14(1), 83-88, DOI: 10.1021/ nl4032549.

44 M. Osswald, E. Jung, F. Sahm, G. Solecki, V. Venkataramani, J. Blaes, S. Weil, H. Horstmann, B. Wiestler, M. Syed, L. Huang, M. Ratliff, K. Karimian Jazi, F. T. Kurz, T. Schmenger, D. Lemke, M. Gömmel, M. Pauli, Y. Liao, P. Häring, S. Pusch, V. Herl, C. Steinhäuser, D. Krunic, M. Jarahian, H. Miletic, A. S. Berghoff, O. Griesbeck, G. Kalamakis, O. Garaschuk, M. Preusser, S. Weiss, H. Liu, S. Heiland, M. Platten, P. E. Huber, T. Kuner, A. von Deimling, W. Wick and F. Winkler, Brain Tumour Cells Interconnect to a Functional and Resistant Network, Nature, 2015, 528(7580), 93-98, DOI: 10.1038/ nature16071.

45 S. Weil, M. Osswald, G. Solecki, J. Grosch, E. Jung, D. Lemke, M. Ratliff, D. Hänggi, W. Wick and F. Winkler, 
Tumor Microtubes Convey Resistance to Surgical Lesions and Chemotherapy in Gliomas, Neuro-Oncology, 2017, 19(10), 1316-1326, DOI: 10.1093/neuonc/nox070.

46 P.-J. Debouttière, S. Roux, F. Vocanson, C. Billotey, O. Beuf, A. Favre-Réguillon, Y. Lin, S. Pellet-Rostaing, R. Lamartine, P. Perriat and O. Tillement, Design of Gold Nanoparticles for Magnetic Resonance Imaging, Adv. Funct. Mater., 2006, 16(18), 2330-2339, DOI: 10.1002/adfm.200600242.

47 C. Alric, J. Taleb, G. Le Duc, C. Mandon, C. Billotey, A. Le Meur-Herland, T. Brochard, F. Vocanson, M. Janier, P. Perriat, S. Roux and O. Tillement, Gadolinium Chelate Coated Gold Nanoparticles As Contrast Agents for Both X-Ray Computed Tomography and Magnetic Resonance Imaging, J. Am. Chem. Soc., 2008, 130(18), 5908-5915, DOI: 10.1021/ja078176p.

48 J.-G. Schloetel, J. Heine, A. F. Cowman and M. Pasternak, Guided STED Nanoscopy Enables Super-Resolution Imaging of Blood Stage Malaria Parasites, Sci. Rep., 2019, 9(1), 4674, DOI: 10.1038/s41598-019-40718-z.

49 L. Theret, A. Jeanne, B. Langlois, C. Hachet, M. David, M. Khrestchatisky, J. Devy, E. Hervé, S. Almagro and S. Dedieu, Identification of LRP-1 as an Endocytosis and Recycling Receptor for $\beta 1$-Integrin in Thyroid Cancer Cells, Oncotarget, 2017, 8(45), 78614-78632, DOI: 10.18632/ oncotarget.20201.
50 Y. Huang, C. Schell, T. B. Huber, A. N. Şimşek, N. Hersch, R. Merkel, G. Gompper and B. Sabass, Traction Force Microscopy with Optimized Regularization and Automated Bayesian Parameter Selection for Comparing Cells, Sci. Rep., 2019, 9(1), 539, DOI: 10.1038/s41598-018-36896-x.

51 T. Yeung, P. C. Georges, L. A. Flanagan, B. Marg, M. Ortiz, M. Funaki, N. Zahir, W. Ming, V. Weaver and P. A. Janmey, Effects of Substrate Stiffness on Cell Morphology, Cytoskeletal Structure, and Adhesion, Cell Motil., 2005, 60(1), 24-34, DOI: 10.1002/cm.20041.

52 S. Munthe, M. D. Sørensen, M. Thomassen, M. Burton, T. A. Kruse, J. D. Lathia, F. R. Poulsen and B. W. Kristensen, Migrating Glioma Cells Express Stem Cell Markers and Give Rise to New Tumors upon Xenografting, J. Neuro-Oncol., 2016, 130(1), 53-62, DOI: 10.1007/s11060016-2221-y.

53 M. L. Broekman, S. L. N. Maas, E. R. Abels, T. R. Mempel, A. M. Krichevsky and X. O. Breakefield, Multidimensional Communication in the Microenvirons of Glioblastoma, Nat. Rev. Neurol., 2018, 14(8), 482-495, DOI: 10.1038/ s41582-018-0025-8.

54 A. Vollmann-Zwerenz, V. Leidgens, G. Feliciello, C. A. Klein and P. Hau, Tumor Cell Invasion in Glioblastoma, Int. J. Mol. Sci., 2020, 21(6), 1932, DOI: 10.3390/ ijms21061932. 